Portland State University

PDXScholar

1986

\title{
Adolescent and parental perceptions of adolescent self-disclosure communication and relational satisfaction
}

Diane S. Lund

Portland State University

Follow this and additional works at: https://pdxscholar.library.pdx.edu/open_access_etds

Part of the Child Psychology Commons, and the Family, Life Course, and Society Commons Let us know how access to this document benefits you.

Recommended Citation

Lund, Diane S., "Adolescent and parental perceptions of adolescent self-disclosure communication and relational satisfaction" (1986). Dissertations and Theses. Paper 3666.

https://doi.org/10.15760/etd.5550

This Thesis is brought to you for free and open access. It has been accepted for inclusion in Dissertations and Theses by an authorized administrator of PDXScholar. Please contact us if we can make this document more accessible: pdxscholar@pdx.edu. 
AN ABSTRACT OF THE THESIS OF Diane $S$. Lund for the Master of Science in Speech Communication presented July $7,1986$.

Title: Adolescent and Parental Perceptions of Adolescent Self-Disclosure Communication and Relational Satisfaction. APPROVED BY MEMBERS OF THE THESIS COMMITTEE:

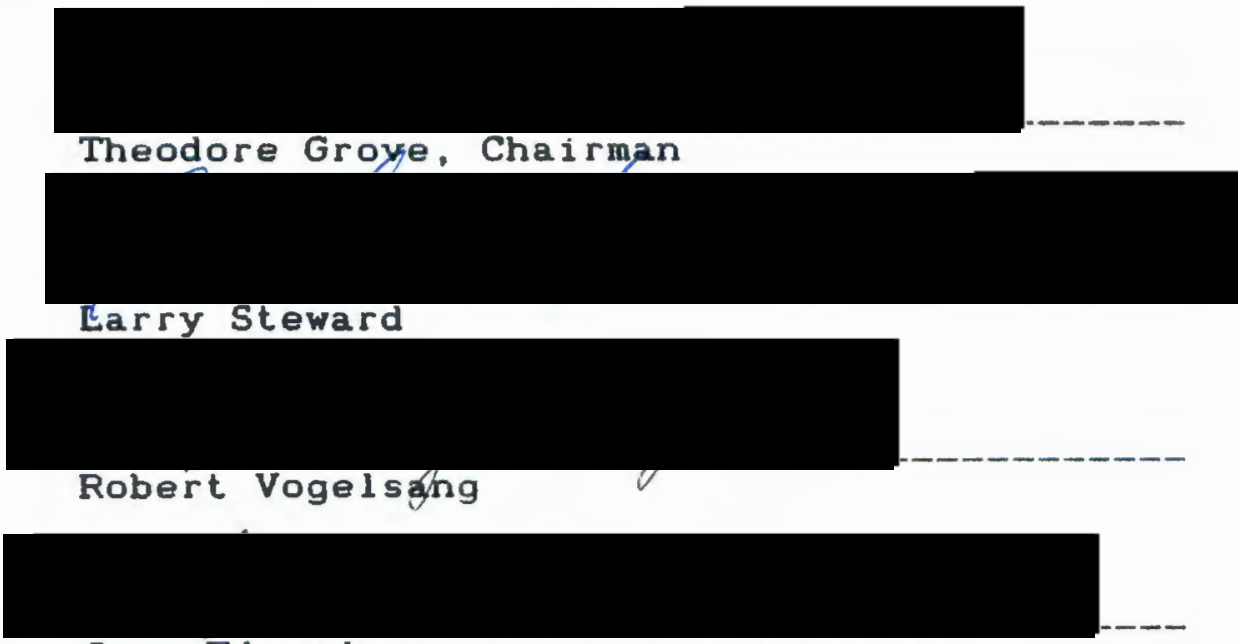

Jean Edwards

As children approach adolescence, their communication relationship with their mothers and fathers undergoes significant transformation. Research has hitherto been conducted on family communication as an isolated variable. This study analyzed adolescent and parental perceptions of adolescent self-disclosure and relational satisfaction by adolescents and parents.

The primary objectives of this investigation were to determine whether there was a relationship between selfdisclosure and relational satisfaction and whether 
adolescents were more willing to self-disclose to their mothers or their fathers. To achieve these objectives, adolescents from eight junior high schools in the Portland metropolitan area and their mothers and fathers independently completed self-report questionnaires which utilized a seven-point Likert scale. These questionnaires included :

A. The Wheeless Self-Disclosure Scales which measured the amount, valence and intimacy level of the selfdisclosure messages.

B. The Weiss Areas of Change Questionnaire which was adapted to the Relational Satisfaction Index for purposes of this study to measure relational satisfaction by parents and adolescents.

Data were analyzed by gender and by grade level for seventh, eighth and ninth graders living in two-parent and single-parent families. Examination of the results suggest that a moderate correlation exists between adolescents' willingness to self-disclose and relational satisfaction with their parents in all families. This relationship becomes stronger between eighth grade boys and their fathers and among seventh and eighth grade girls and their mothers. The research also demonstrates that fathers are the prime conduit of self-disclosure messages in two-parent families. This latter finding was confirmed in reports completed by fathers and mothers. Implications of the findings are discussed. 
ADOLESCENT AND PARENTAL PERCEPTIONS OF ADOLESCENT SELF-DISCLOSURE COMMUNICATION AND RELATIONAL SATISFACTION

by

DIANE S. LUND

A thesis submitted in partial fulfillment of the requirements for the degree of

\author{
MASTER OF SCIENCE \\ in \\ SPEECH COMMUNICATION
}

Portland State University 
TO THE OFFICE OF GRADUATE STUDIES AND RESEARCH:

The members of the Committee approve the thesis of

Diane S. Lund presented July 7,1986

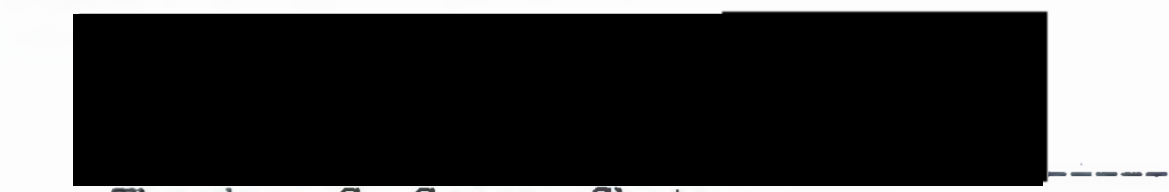

Theodore G. Grove, Chair

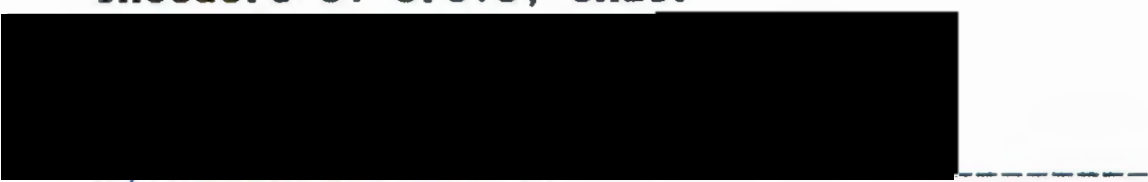

Larry Steward

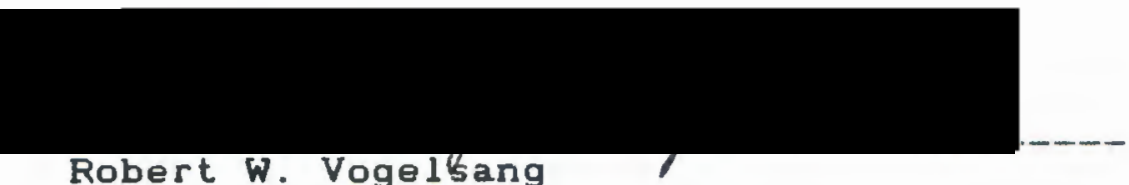

Robert W. Vogelsang

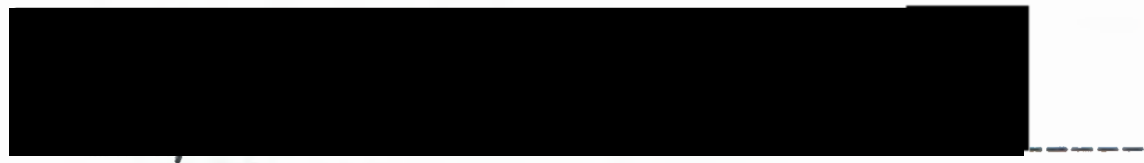

Jean Edwards

APPROVED :

Theodore G. Grove, Head, Department of Speech Communication 


\section{ACKNOWLEDGEMENTS}

As the parent of an adolescent daughter and as a former junior high school teacher, this author has experienced communication problems with young adolescents firsthand. Innumerable friends, also the parents of adolescents, have frequently complained about communication breakdowns in their families. After learning about this study, their typical response has been, "We can't talk to our teenager. If you find anything to help, please let us know."

The need for this study was confirmed after taking an adolescent psychology class at Portland State University from Associate Professor Gerald Guthrie in 1983. During that class this author learned about the developmental characteristics of teenagers and the lack of understanding of teenagers by their parents and other adults.

During the summer of 1983 , this author met with a pioneer in the field of adolescent psychology, Gisela Konopka. She surveyed a stratified sample of 1,000 adolescent girls from throughout the United States in 1974 . Among the questions asked during the interview session was whether the girls had any communication problems with adults, notably their parents. A significant number of girls responded by saying adults refused to listen to their ideas 
and instead would yell and nag at them, treating them with little or no respect. The girls urged adults to understand their needs and to improve their communication skilis (Konopka, 1976).

It is hoped that this empirical study will address some of the communication problems that exist between parents and their young adolescents, thereby helping to clarify how those relationships work.

This author is deeply indebted to Dr. Theodore Grove, head of the Speech Communication Department at Portland State University, for his invaluable assistance. Without him, this study would never been completed. He gave tirelessly of his time, even when the press of other business interfered, by helping define the study and working through its niches. He lent considerable expertise to the compilation of data and statistical analysis. It was indeed a pleasure working with him. I appreciate his diligence, concentrated effort and insistence that the study be carefully planned out and adhere to strict academic guidelines.

Dr. Larry Steward offered considerable guidance, particularly during the development of the prospectus. He was gracious about listening to my concerns and always had positive words of encouragement. The other member of my faculty committee from the Speech Communication Department at Portland State University, Dr. Robert Vogelsang, offered 
$\mathbf{v}$

invaluable assistance as did West Brenner, head of Academic Computing Services, Dr. Gerald Guthrie, associate professor in the Psychology Department, and Dr. Dave Capuzzi, associate professor in the Education Department.

Finally, my daughter, Elisa, lent me considerable support, especially during the early stages when I was gathering participants for this research project. 


\section{TABLE OF CONTENTS}

PAGE

ACKNOWLEDGEMENTS . . . . . . . . . . . . . . . . . . . i ii

LIST OF TABLES

.viii

CHAPTER

I INTRODUCTION . . . . . . . . . . . . . . . . . 1

Literature Review. . . . . . . . . . . 2

Purpose of Study . . . . . . . . . . . . . 9

I I METHODOLOGY . . . . . . . . . . . . . . . . . 14

Definitions . . . . . . . . . . . . . . . . 14

Procedural Overview . . . . . . . . . . . 15

Subjects . . . . . . . . . . . . . . . 16

Sampling Method... . . . . . . . . . . . 17

Instrumentation . . . . . . . . . . . . 20

Data Analysis... . . . . . . . . . . . 24

II I RESULTS . . . . . . . . . . . . . . . . . . . 25

Reliability Study . . . . . . . . . . . . 25

Analysis of Primary Hypotheses . . . . . . 28

Hypothesis I . . . . . . . . . . . . . 29

Hypothesis II............. . 32

Hypothesis III . . . . . . . . . . . . 36

Hypothesis IV . . . . . . . . . . . . . . 39

Follow-up Analyses . . . . . . . . . . . . 48 
Primary Hypotheses . . . . . . . . . . 58

Follow-Up Analyses . . . . . . . . . . . 63

IV

Limitations............... . . 70

Implications . . . . . . . . . . . . . 71

Recommendations... . . . . . . . . . 73

REFERENCES . . . . . . . . . . . . . . . . . . 74

APPENDIX A . . . . . . . . . . . . . . . . . . 80

APPENDIX B . . . . . . . . . . . . . . . . . 82 


\section{LIST OF TABLES}

TABLE

PAGE

I Reliability Scores for the Self-Disclosure and

the Relational Satisfaction Instruments. . .

I Reliability Scores by Factor for the Self-

Disclosure Instrument . . . . . . . . . . .

II Relationship Between Adolescent Reports of Self-

Disclosure to Fathers and Fathers' Perception of Self-Disclosure for all Families..... .

IV Relationship Between Adolescent Reports of Self-

Disclosure to Mothers and Mothers' Perception

of Self-Disclosure for all Families.....

$\checkmark$ Relationship Between Adolescent Reports of Self-

Disclosure and Adolescent Relational

Satisfaction to Mothers for all Families...

VI Relationship Between Adolescent Reports of Self-

Disclosure and Adolescent Relational

Satisfaction to Fathers for all Families. . . 35

VII Relationship Between Adolescent Reports of Self-

Disclosure to Mothers and Mothers'

Relational Satisfaction with Adolescents

for all Families. . . . . . . . . . . . . . 
VII Relationship Between Adolescent Self-Disclosure to Fathers and Fathers' Relational Satisfaction with Adolescents for all Families....................... . . . . 39

IX Comparison of Mothers' Versus Fathers' Receipt of Self-Disclosure for all Families..... .

$X$ Relationship Between Adolescent Reports of SelfDisclosure to Mothers and to Fathers for all Families. . . . . . . . . . . . . . . . .

XI Comparison of Adolescent Reports of SelfDisclosure to Mothers Versus Fathers within Two-Parent Families.

XI Comparison of Adolescent Reports of SelfDisclosure by Grade Level with Fathers within Two-Parent Families. . . . . . . . .

XII Comparison of Adolescent Reports of SelfDisclosure by Grade Level with Mothers within Two-Parent Families.............

XIV Comparison of Adolescent Reports of SelfDisclosure with Mothers Versus Fathers for all Families

XV Relationship Between Adolescent Relational Satisfaction with Mothers and Fathers for all Families. . . . . . . . . . . . . . . . 
XVI Comparison of Adolescent Relational Satisfaction with Mothers Versus Fathers within Tro-parent Families. . . . . . . . . . . . .

XVII Comparison of Adolescent Relational Satisfaction with Mothers Versus Fathers for all Families.

XVIII Comparison of Adolescent Relational Satisfaction by Grade Level with Fathers within Tro-Parent Families. . . . . . . . . . . . . . 56

XVIV Comparison of Adolescent Relational Satisfaction by Grade Level with Mothers within TwoParent Families. . . . . . . . . . . . . . .

XX Relationship Between Adolescent Relationa 1

Satisfaction with Mothers and Mothers'

Relational Satisfaction with Adolescents for all Fanilies................ . 54

XXI Relationship Between Adolescent Relational

Satisfaction with Fathers and Fathers'

Relational Satisfaction with Adolescents

for all Families.................. . 54

XXII Relationship Between Mothers' and Fathers'

Perception of Adolescent Self-Disclosure

for all Families.................. . . . . . . .

XXIII Relationship Between Mothers' and Fathers'

Relational Satisfaction with Adolescents

for all Families. . . . . . . . . . . . . . . 55 
XXIV Comparison of Fathers' Versus Mothers'

Relational Satisfaction with Adolescents

for all Families... . . . . . . . . . . . . 56

XXV Relationship Between Mothers' and Fathers'

Perception of Adolescent Self-Disclosure

and Relational Satisfaction for all Families. 


\section{CHAPTER I}

\section{INTRODUCT ION}

During adolescence, the parent-child relationship undergoes transformation. Striving for independence, adolescents spend less time talking to their parents and share their intimate thoughts with friends (Mussen, Conger and Kagan, 1969). Self-disclosure, an important part of the communication process, is the primary conduit for personal information exchange (Jourard, 1958; Chelune, 1981). Lack of self-disclosure is typical among adolescents and their mothers and fathers (Pasley and Gecas, 1984).

Yet researchers have shown that adolescents want to achieve better communication with their parents (Konopka, 1976). Adolescents feel reluctant about sharing such personal information. They are uncertain whether their thoughts will be acceptable to their parents, and they perceive their parents as unwilling to listen to their concerns (Norrel1, 1984).

Satisfaction within the family is a function of the sum total of observations by family members, coupled with an interpretation of those events. The exchange of pleasant and unpleasant behavior among mothers and fathers and their 
adolescents has a significant effect on the level of satisfaction within that relationship (Grounds, 1979). The salutary effect of satisfaction on family relationships was confirmed in Grounds' research. However. Grounds did not specifically examine the relationship between satisfaction and communication behavior among family members.

This study explores how self-disclosure functions within family units. It examines how adolescent selfdisclosure to their parents is associated with relational satisfaction of family members so we can begin to understand some of the complexities of parent-adolescent communication. There exists considerable literature on self-disclosure behavior as an endogenous and exogenous variable associated with various aspects of face-to-face interaction on the one hand, and on communication problems within the family on the other. Both corpora are spread across the scholarly journals of several academic disciplines including social psychology. education, counseling and speech communication.

\section{LITERATURE REVIEW}

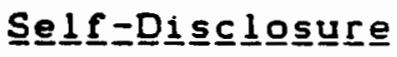

It was Jourard (1958) whose scholarly work brought academic respectability to the concept of self-disclosure in the 1950's. Jourard described self-disclosure as a personality construct. He said it occurred whenever someone 
made him/her self known to others. His work supported the assumption that the ability to present such self-disclosure messages is one identifying characteristic of a healthy personality.

Since Jourard's time the definition of self-disclosure has been elaborated. Cozby (1973) called self-disclosure a process of interaction as opposed to a personality construct. Such a process occurs voluntarily without any force or threats in an interpersonal exchange (Pearce and Sharp, 1973). Appropriate self-disclosure brings about increased trust, liking, loving and a greater attraction for the other person (Rosenfeld, 1979).

Self-disclosure is a major factor in developing interpersonal relationships (Goodstein and Reinecker, 1974). Piaget said the ability to reveal personal thoughts to others is a critical process in the development and functioning of thought (Piaget, 1962; Vondracek and Vondracek, 1971). Chelune (1981) included the verbal and non-verbal exchange of information under the rubric of selfdisclosure. He said miscommunication could occur if the disclosure message is not perceived correctly by the recipient, thereby leading to negative consequences and nonreciprocal disclosures. Self-disclosure messages can clarify personal beliefs, enhance social validation of personal concepts and become a way of expressing emotional experiences.

Self-disclosure does not occur in a vacuum. The 
discloser always needs a topic, a target, a relationship and a situation (Chelune, 1979). The need to link selfdisclosure to other variables and not regard the concept as an isolated construct also received support from Waterman (1979) who suggested that self-disclosure was related to the amount, content and intimacy level of the message. She said self-disclosure should be considered by looking at the family's boundary system and determining whether it has open or rigid rules. Waterman stressed "the most pressing need seems to be for an application of research methods to family dynamics" theories" (Waterman, 1979). Tardy, Hosman and Bradac ( 1981 ) confirmed the need to determine how the factors of self-disclosure influence communication, such as honesty, valence, intimacy, amount, target and topic variations as well as sex role.

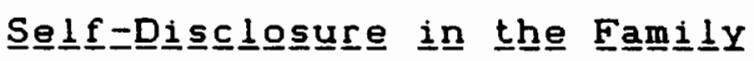

Looking at self-disclosure from a family dynamics perspective, Satir indicated that the analysis of selfdisclosure messages should involve communication styles (Satir, 1967). The congruent message, characterized by clarity, simplicity and precision with a lack of criticism, is the most effective style according to Satir. Within that style, the message can be clearly understood, and the words match the intended effect.

Gender differences in self-disclosure levels have been 
substantiated numerous times (Jourard and Lasakow, 1958; Rivenbark, 1971; Greenblatt, Freimuth and Hasanauer, 1980; Lovins,1976; Rosenfeld, 1979; ONeill, Fein, Volit and Frank; 1976; Snoek and Rothblum, 1979). All these investigators concluded that females were higher selfdisclosers than males.

Several explanations were given for these findings. Chelune (1976) said women are expected to be more expressive and open, while men are seen as silent and strong. Jourard (1971) argued that women are judged according to their success in personal relationships whereas men fear the rejection and ridicule that occurs by violation of societal expectations.

Studies on self-disclosure patterns in families confirm that adolescent girls disclose at higher levels to their mothers than to their fathers (Rivenbark, 1971 ; Jourard and Lasakow, 1958; Pedersen and Highbee, 1969). Rivenbark (1971) offered a rationale for this finding. He reported that mothers found self-disclosure messages from their children more personally satisfying than fathers did.

Other investigators have examined communication processes in general. Mothers felt they had better communication with their adolescents than fathers (Barnes and 0lson, 1985). However, when the adolescents were asked which parent they communicated with most of ten, no clear favorite emerged. Barnes and olson also found that adolescents reported difficulty communicating with both 
their parents. When adolescents were asked which parent they communicated with most frequently, no significant differences were reported between adolescent girls and boys (Norrel1, 1984).

Researchers acknowledged there had been little focus on the relationship between parent-adolescent communication and family functioning (Tims and Masland, 1985). When such intergenerational studies have been conducted, parents and adolescents reported remarkably different scores about the significance of communication on their family relationships, according to Tims and Masland (1985).

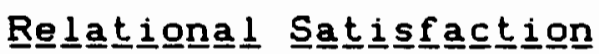

As one might expect, relational satisfaction definitely influences the communication process. In a study involving 208 normal families, one investigator found a higher degree of communication between adolescents and their parents when satisfaction levels were higher (Norrell, 1984). Adolescents acknowledged a greater willingness to disclose to those whom they perceived as warm and accepting.

When Margolin conducted a study linking martial satisfaction with the communication process, she found a negative relationship (Margolin, 1978). Studying 27 distressed couples who were referred to counseling. Margolin found an inverse relationship between communication and self-reports of satisfaction. This led Margolin to conclude 
that "poor communication may be the earmark of marital distress but it appears from these data that the intensity of the communication deficit does not correspond systematically with the level of overall distress."

Weiss, Hops and Patterson (1973) looked at marital satisfaction by observing pleasurable and displeasurable behavior and demonstrated that global ratings of satisfaction could be successfully separated into various components. Weiss and Margolin (1977) defined problems in marital relationships as the presence of conflict and discord.

When parent-adolescent relationships were examined. Grounds (1984) acknowledged that the exchange of pleasant and unpleasant behavior had an effect on satisfaction. She found that aversive, displeasing events produced dissatisfaction within families and said that the rate at which behavioral events occurred was associated with the relative level of family distress.

When they studied the frequency of specific behavior, Jacob and Seilhamer (1984) found that distressed family relationships led to a high degree of dissatisfaction. They concluded that childhood problems were related to marital discord, particularly in alcoholic families, and said there were few report procedures available to describe such problematic parent-adolescent interaction.

Marital and family relationships have not been the only areas investigated by researchers interested in relational 
satisfaction. Foeller (1984) analyzed the relationship of interpersonal communication and satisfaction between patients and their physicians. She concluded that patients who expressed higher levels of communication satisfaction with their physicians indicated more satisfaction with their quality of medical care.

Another investigator, Hecht, (1978a) suggested that satisfaction was crucial to psychological health and an important construct in communication behavior. Hecht stated that "the study of self-disclosure, for example, would profit from the empirical investigation of the situations in which disclosure is satisfying or dissatisfying. The study of communication satisfaction should facilitate the examination of the role of communication in relationship development" (Hecht, 1978a).

Hecht acknowledged that communication satisfaction was a neglected empirical variable in interpersonal communication research and has received little theoretical and empirical attention. He suggested studying the relationship between satisfaction and other variables such as sex, stability and length of relationship (Hecht, 1978b).

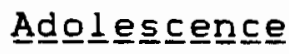

The idea of adolescence as a separate phase of development was introduced by Hall in the early twentieth century (Hall, 1904, 1905; Conger, 1973). He identified this 
period as a significant time of storm and stress. Later Freud called adolescence a developmental stage that results from the physiological changes accompanying puberty (Freud, 1953). Erikson (1968) identified adolescence as a time of identity confusion within a young person's life, characterized by an "internal physical, physiological and cognitive revolution."

Adolescence is characterized by several factors. including the onset of puberty, peer group influence, the search for self-identity, the struggle for independence from parental authority. societal growth and participation in "make-believe" organizations at school and in civic groups (Campbel1, 1969). Campbell suggested that most parent-child conflicts emerge during early adolescence, between the ages of 12 and 14. Kagan (1972) agreed with these age delineations, adding that adolescence emerges when the child begins examining the consistency of his/her beliefs and becomes preoccupied with achieving autonomy. Douvan and Adelson (1966) maintained that childhood comes to an end by age 13, with the adolescent and parent finding themselves at departure points as the adolescent begins to emancipate histher self.

PURPOSE OF STUDY

Regardless of how families behave in familial interactions, perceptions of their own and one another's 
behavior and attitudes form the primary basis for their interaction. These perceptions are the primary data of familial relationships and represent how family members think and what they believe other members think.

Taken singly the expressed perception of a family member is merely a subjective report. However, these reports take on significance when viewed in the context of a family relational system. Compared to perceptual reports from other family members, such data provide an objective description of the relational characteristics within the family unit. For example, an adolescent daughter could report high selfdisclosure to her mother, while her mother reports receiving low self-disclosure. This system of relational perceptions comprises an objective reality within which mothers and daughters continue to interact. An important part of this study is to explore the intricacies of familial relationships with respect to perceived self-disclosure and relational satisfaction sampled from a large number of ongoing family units that represent a heterogeneous population.

Adolescents and their parents were sought for this study because generalizations drawn from a posㅡㄴ hoo sample were not considered applicable. Miller and Sunnafrank (1984) questioned the utility of studying familial relationships through post hoo data from groups such as college sophomores rather than directly sampling from cohabiting family members. They contended there are lurking doubts about 
theories gained from such sample groups, and concluded that "scientifically viable communication theory must be at least potentially capable of shedding light on real world communication transactions."

Previous research has concentrated on self-disclosure between adolescents and their parents. There has been little research reported in the scholarly journals assessing the association between self-disclosure and relational satisfaction within current ongoing family systems. The present study is aimed at filling an important gap in research because such findings are important for understanding the dynamics of family relationships when children are in adolescence.

This study involved data collection on self-disclosure reports by adolescents to their parents and the perceptions of that self-disclosure by parents. Correlations between self-disclosure and relational satisfaction between adolescents and their parents were computed and analyzed. The following hypotheses were examined:

Hypothesis I. There will be a moderately strong positive relationship between adolescents' reported selfdisclosure and parents' report of their adolescents' selfdisclosure (Daluiso, 1972; Jacob, Grounds and Haley, 1982 ; Jackson, 1965; Pearce and Sharp, 1973; Prinz, Rosenblum and O'Leary, 1978; Rosenfeld, 1979). Researchers have cited the necessity of understanding the relationship between selfdisclosure and the perception of that self-disclosure within 
families. This hypothesis will explore the nature (if any) and strength of that relationship.

Hypothesis II. There will be a moderately strong positive relationship between adolescents' reported selfdisclosure and adolescents' expressed satisfaction about communication with their parents (Bradac, Hosman and Tardy, 1980; Chelune, 1981; Cozby, 1973; Doster and Strickland, 1969; Gilbert, 1976; Hecht, 1978b; Konopka, 1976). Although there has been very little empirical research on this topic. researchers have suggested that the perception of family functioning would effect adolescents' willingness to selfdisclose.

Hypothesis III. There will be a moderately strong positive relationship between adolescents' reported selfdisclosure and parents' expressed satisfaction with their relationship with their adolescents (Gilbert, 1976; Hecht, 1978b; Waterman, 1979). Researchers have cited the importance of linking self-disclosure reports to indicators of familial relationships such as relational satisfaction. Hypothesis IV. Mothers will report receiving significantly more self-disclosure from their adolescents than fathers will report receiving (Daluiso, 1972; Jourard and Lasakow, 1958; Pedersen and Highbee, 1969; Rivenbark, 1971). The research literature is replete with findings that adolescents are more willing to self-disclose to their mothers than to their fathers. However, some of these reports are based on anecdotal data, small samples and 
methods that do not assure anonymity. This hypothesis will

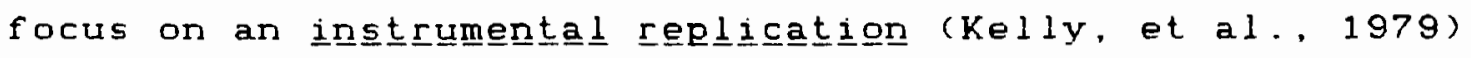
of those findings using the large data sample from the present study. 
CHAPTER I I

METHODOLOGY

DEF INITI ONS

For this study the following terms will be defined: self-disclosure, amount of self-disclosure, intimacy level of self-disclosure, valence of self-disclosure, early adolescence, family satisfaction and the family triad.

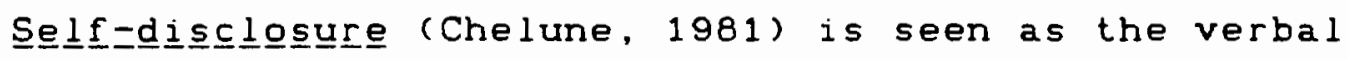
exchange of personal information whereby the adolescent makes his/her self known to his/her parent by clarifying personal beliefs and sharing emotional experiences.

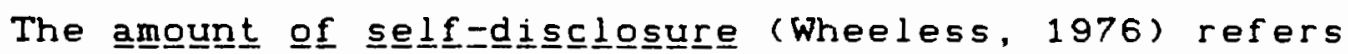
to the frequency and duration of self-disclosure messages

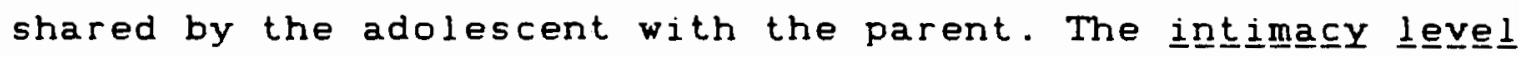
(Wheeless, 1976) represents the depth of disclosure and the revealing of information not readily available to the recipient. The intimacy level is the most profound. Intimate thoughts are shared without doubt or hesitation. Vaalengen (Wheeless, 1976) refers to the positivity or negativity of the self-disclosure message, with both good and bad feelings and experiences shared by the adolescent. 


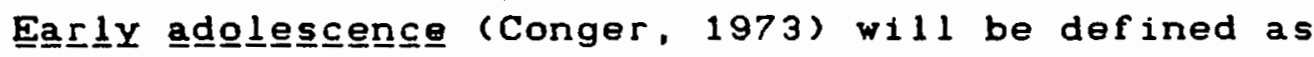
seventh, eighth and ninth graders between the ages of 11 and 14. During this age span, youngsters have entered puberty. begun achieving independence, started participating in organizational activities outside their home and embarked on their search for identity. As mentioned in the literature review, this is the age when most parent-child conflicts start to emerge.

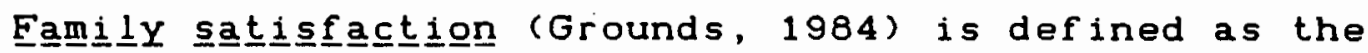
degree to which the adolescent feels comfortable in the relationship and desires no change in the parents' behavior toward him/her.

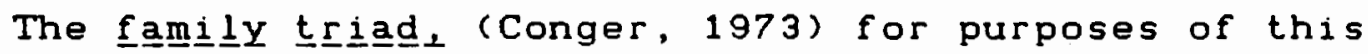
study, consists of the mother, father and adolescent.

\section{PROCEDURAL OVERVIEW}

This study involved parents and their adolescents, representing 341 families, who completed self-disclosure and relational satisfaction questionnaires independently.

Families were identified and contacted from eight junior high schools scattered around four school districts in the Portland metropolitan area. Following the completion of these questionnaires, reliability tests were computed. The questionnaire results were analyzed with respect to four hypotheses and thirteen follow-up analyses, utilizing the Pearson product-moment correlation coefficient ( $r$ ), the t- 
test of mean differences ( $t$ ) and the analysis of variance (F).

\section{SUBJECTS}

To obtain participants in this study, principals from eleven public and private junior high schools in the Portland metropolitan area were contacted. Eight schools agreed to participate. The public schools were Whitford Intermediate and Highland Park Intermediate Schools in the Beaverton District, Lake Oswego Junior High School in the Lake Oswego District, Fowler and Twality Junior High Schools in Tigard and Moss Junior High in Oregon City. The private schools were Oregon Episcopal and Catlin Gabel, which are located in Portland. Drawing on both rural and urban settings, these eight schools represent a cross-section of low, middle and upper socio-economic families from the Portland metropolitan area.

Establishing early contact with potential sources of participating families was considered essential to obtain approval from these schools. The investigator began contacting principals in May, 1984, five months before making the presentations. Before consenting, several principals had to obtain approval from their school boards and/or administrators. During the summer, financial aid and in-kind support were solicited and packets prepared for parents and students.

To fund this study, the researcher solicited $\$ 1,500$ in 
contributions from the communtty. Funds were disbursed through a short-term research project account set up by the Portland State University Foundation.

\section{SAMPLING METHOD}

Parents received informational packets while attending Back-to-School-Night during September and October, 1984. This is a yearly event held at junior high schools, which most parents attend to learn about the academic goals for the coming year and to meet their students' teachers. Approximately 250 parents attended meetings where presentations were made. Those who were interested took informational packets home.

Before the presentation, some schools had sent letters, informing parents about the research project. At two schools, Moss and Highland Park, the investigator met with representatives from the parent clubs before the presentation, to gain their support for this research study.

At Back-to-School-Night, parents were told about the study and guaranteed anonymity. Those who were interested received an envelope containing a letter of introduction explaining the purpose of the research project, a consent form, which would allow their adolescents to participate, self-disclosure and relational satisfaction questionnaires (see Appendix A) printed on different colored paper, a Scantron sheet to record their answers and a sharpened 
pencil. Parents also were asked to include their

adolescent's name, grade and school. These parents completed the questionnaires at home and were encouraged not to confer with each other prior to completion of the questionnaires. They were asked to complete the questionnaires within five days, then place all the materials back inside the envelope and drop it in the mail. The envelopes were self-addressed to Portland State University and postage was covered by funds from the research project's Foundation account. To remind parents about the questionnaires, announcements were printed in the schools' newsletters.

A first person scenario from a parent might have been: "I came to Back-to-School-Night and heard an investigator describe a project involving adolescent communication and family satisfaction. I was told this project could potentially help me communicate better with my adolescent child."

Students, whose parents participated, completed the questionnaires at school outside of class and were, therefore, not influenced by their parents' responses. Teachers were given instructions to read aloud before students completed the questionnaires. Students received materials' packets with the self-disclosure and relational satisfaction questionnaires, a consent form (see Appendix B) and a sharpened pencil. The students also answered questions related to their age, sex, school, which parent(s) they lived with and with whom they spoke most of ten. 
Although the student's name was on the outside of the envelope, once the packets were returned, their names were blotted out and a family identification number was inserted. The investigator picked these packets up from the individual schools.

An adolescent who heard a presentation might have said. "I was in class and heard my teacher talk about a research project that involved communication with my parents and how satisfied I was with their behavior toward me. I was told this project could potentially help me get along better with them."

of 1,000 packets distributed at eight schools, 341 were returned. Of those, 21 families had to be eliminated from the study because the parents either refused to sign a consent form or the adolescent was unwilling to participate in the study. Each family was assigned a three-digit identification number at random. No names were associated with this number. Although there was an overall 34 percent response rate by parents, the rate was significantly higher at those schools which allowed the investigator to make a presentation before the entire parent group. At three schools, Fowler Junior High, Catlin Gabel and Lake Oswego Junior High, the principals requested that such a format not be followed. At Fowler Junior High and Catlin Gabel, the principals made the announcement, and the investigator stood in back of the room handing out packets to interested parents. At Lake Oswego Junior High, the investigator was 
only allowed to speak in front of four small (28) groups of parents rather than the entire group. These three schools had a much lower response rate. By distributing packets individually or in a smaller group. parents might have feared a loss of anonymity if they participated in this study.

Parents and schools were assured that they would be notified of the results. They were told that after this study was completed, the coded number on the consent forms and questionnaires would be deleted and the consent forms and questionnaires stored in separate files so there would be no way for anyone but the investigator to match parents with adolescents. All of the involved schools would be notified of the results. All these procedures met with the approval of Portland State University Human Subjects Research Review Committee.

\section{INSTRUMENTATION}

Adolescent willingness to self-disclose and parental perceptions of that self-disclosure were measured by using the scores on the Self-Disclosure Scales (SDS) devised by Lawrence wheeless (1976). The SDS consists of five sub-

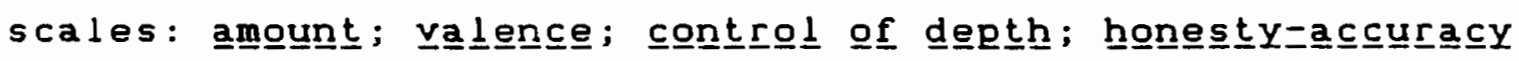

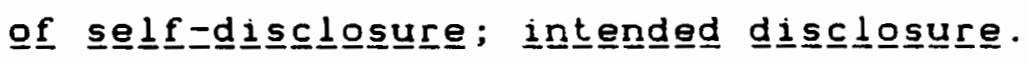

The SDS was developed and validated through three generations of simple regression, multiple regression and 
factor analytic studies (Wheeless and Grotz, 1975: Wheeless and Grotz, 1976; Wheeless, 1976). The five-factor solution was replicated on a revised 40-item instrument. Reliabilities for the five replicated factors in this current version of the instrument were as follows: amount = +.85 ; valence $=+.87$; control of depth $=+.79$; honestyaccuracy $=+.85$; intended disclosure $=+.70$ (Wheeless. 1976). The whole scale has been found to correlate with theoretically related constructs such as solidarity, trust and empathy (Wheeless and Grotz 1977), while retaining measurement specificity to the self-disclosure component. Only three factors of the self-disclosure scale were used for this study - amount, valence and control of depth. It was felt that the other factors, honesty-accuracy and intended disclosure, were not pertinent for an adolescentparent study of self-disclosure because the questions were geared to adults. For example, "I cannot reveal myself when I want to because I do not know myself thoroughly enough," and "When I am self-disclosing. I am consciously aware of what I am revealing."

The Relational Satisfaction Index (SI) was modelled after the Areas of Change Ouestionnaire ( $A C Q$ ), which identified specific, behaviorally defined areas of dissatisfaction within a marriage (Weiss, et al., 1973). It asked the partners to evaluate their relationship by indicating the amount of change they desired. The ACO was developed to look at marital complaints (Weiss and Birchler 
1975). During their research project, Margolin, Talovic and Weinstein (1983) found substantial support for concurrent validity of the $A C Q$ as a measure of overall marital satisfaction.

Then, Jacob and Seilhamer (1984) adapted the ACQ to measure parent-child satisfaction. Changing the instrument's name to the Parent Child-Areas of Change Questionnaire (PC$A(Q)$, these researchers developed 34 questions for parents and 32 questions for children. Designed for adolescents above the the fifth grade level and their parents (Jacob and Seilhamer, 1984), the PC-ACQ was utilized in conjunction with follow-up procedures. After completing the questionnaire, parents and their children discussed conflict issues during interview sessions, then in a laboratory setting. Jacob and Seilhamer (1984) found that the PC-ACQ parent form produced a Cronbach alpha of +.94 , for children. the level was +.96 , and the levels were $+.91,+.93,+.93$ and +.94 , respectively, for the mother-child, father-child. child-mother and child-father reliabilities.

Grounds utilized this same instrument, however she changed its name to the Family Areas of Change Questionnaire (FACQ) (Grounds and Jacob, 1980; Grounds, 1984). FACQ parent scores were compared with the Interaction Behavior Questionnaire (dyad score), the Interaction Behavior Questionnaire (child score), and the Behavior Problem Checklist developed by Grounds (1984). The FACQ generated validity coefficients of $r=+.60, r=+.76$, and FACQ scores 
were derived as $r=+.63$, respectively (Grounds, 1984). It was proven to have face, content and construct validity and significant correlations on inter-observer reliability tests. Grounds used the FACQ while studying parentadolescent interaction for her Ph.D. dissertation from the University of Pittsburgh (Grounds, 1984).

The SI asks adolescents to indicate the amount of change they would like to see in their mother's and their father's relationship to them, such as paying more attention to their activities, not hassling them about chores and giving them all the money they need. Then the parents complete the questionnaire, indicating behavior they would like to see changed in their adolescent. After the SI is completed and the scores compiled for both the parents and their adolescents, high scores are considered indicative of low satisfaction, while lower scores indicate a higher satisfaction level in the relationship. However for this present study, Grounds suggested, in a personal interview. that the questionnaire be slightly reworded to indicate the degree of satisfaction rather than the degree of change desired within the relationship by adolescents and their parents. This was accomplished such that high scores on the SI indicated high relational satisfaction for the present study.

Several questions from Grounds' FACQ were not used during this study because they were not relevant to seventh. eighth and ninth graders. Those questions dealt with issues 
such as driving and dating behavior. The SI and the SD questionnaires utilized a seven-point Likert scale. Approval was obtained from the researchers. Linda Grounds and Lawrence Wheeless, respectively to use the FACQ and the SDS testing instruments for this research project.

\section{DATA ANALYSIS}

In analyzing the data, Hypotheses I, II and III were assessed using the Pearson product-moment correlation coefficient. Hypothesis IV was assessed by applying the $t$ test of mean differences. Beyond these primary hypotheses, subsequent analyses also utilized the Pearson product-moment correlation coefficient, the $t$-test of mean differences and the analysis of variance. All the data analyses of the present study were assisted by the "RELIABILITY" "PEARSON CORR," "T-TEST" and "ANALYSIS OF VARIANCE' subprograms of the STATISTICAL PACKAGE FOR THE SOCIAL SCIENCES (HuII and Nie, 1981) on a Honeywel1 6640 computing system. 


\title{
CHAPTER I I I
}

\author{
RESULTS
}

\section{REL I AB I L ITY STUDY}

A Cronbach Standardized Item Alpha Reliability Coefficient was computed for the theeless Self-Disclosure instrument. For mothers the reliability coefficients were +.77 , for fathers +.88 , for adolescents to mothers, +.78 and for adolescents to fathers, +.80 (see Table I). These sample groups were pooled into a parent and an adolescent group, producing similar findings. For mothers and fathers the scores were +.78 and for adolescents to mothers and adolescents to fathers, +.79. For mothers, fathers and adolescents to mothers, the scores were +.77. The reliability coefficient for mothers, fathers and adolescents to fathers was +.78 . Overall reliability for all respondents was +.78 .

Subsequently these reliabilities were computed separately for the three factors within the wheeless Self-

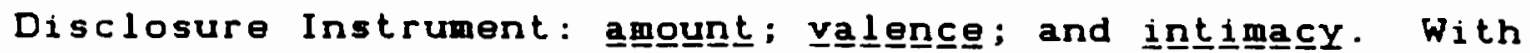
respect to amount, there was consistency among the reliability scores. For mothers the scores were +.81 , for 
fathers, +.78 , for adolescents to mothers, +.80 and for adolescents to fathers, +.81. Valence was the next factor considered and reliability tests were computed for all sample groups. For mothers the scores were+.77, for fathers, +.78 , for adolescents to mothers, +.82 and for adolescents to fathers, +.75. The reliabilities for intimacy were the lowest among the factors. Mothers showed scores of +.69 , fathers, +.70 , adolescents to mothers, +.57 and adolescents to fathers, +.70 (see Table II).

Again sample groups were combined and reliabilities run by factors. For amoungt, a pooled sample of mothers, fathers and adolescents to mothers showed a coefficient of +.80 , and for mothers, fathers and adolescents to fathers, the scores registered were +.81 . The val 1 ence +.79 for a pooled sample of mothers, fathers and adolescents to mothers, and +.76 for mothers, fathers and adolescents to fathers. Intiㅗ프도 was the third factor considered. Combined sample groups showed reliabilities of +.65 for mothers. fathers and adolescents to mothers, and scores of +.70 for mothers, fathers and adolescents to fathers.

Cronbach Alpha reliabilities also were performed on the Relational Satisfaction questionnaire (SI). The scores were much higher than for the Self-Disclosure Instrument. On the SI, the scores for mothers were+.90, for fathers+.90, for adolescents to mothers +.93 and for adolescents to fathers +.94 . When sample groups were combined, mothers and fathers produced a coefficient of +.98 and adolescents to mothers 
and adolescents to fathers had a reliability score of +.93.

TABLE I

RELIABILITY SCORES FOR THE SELF-DISCLOSURE AND THE RELATIONAL SATISFACTION INSTRUMENTS

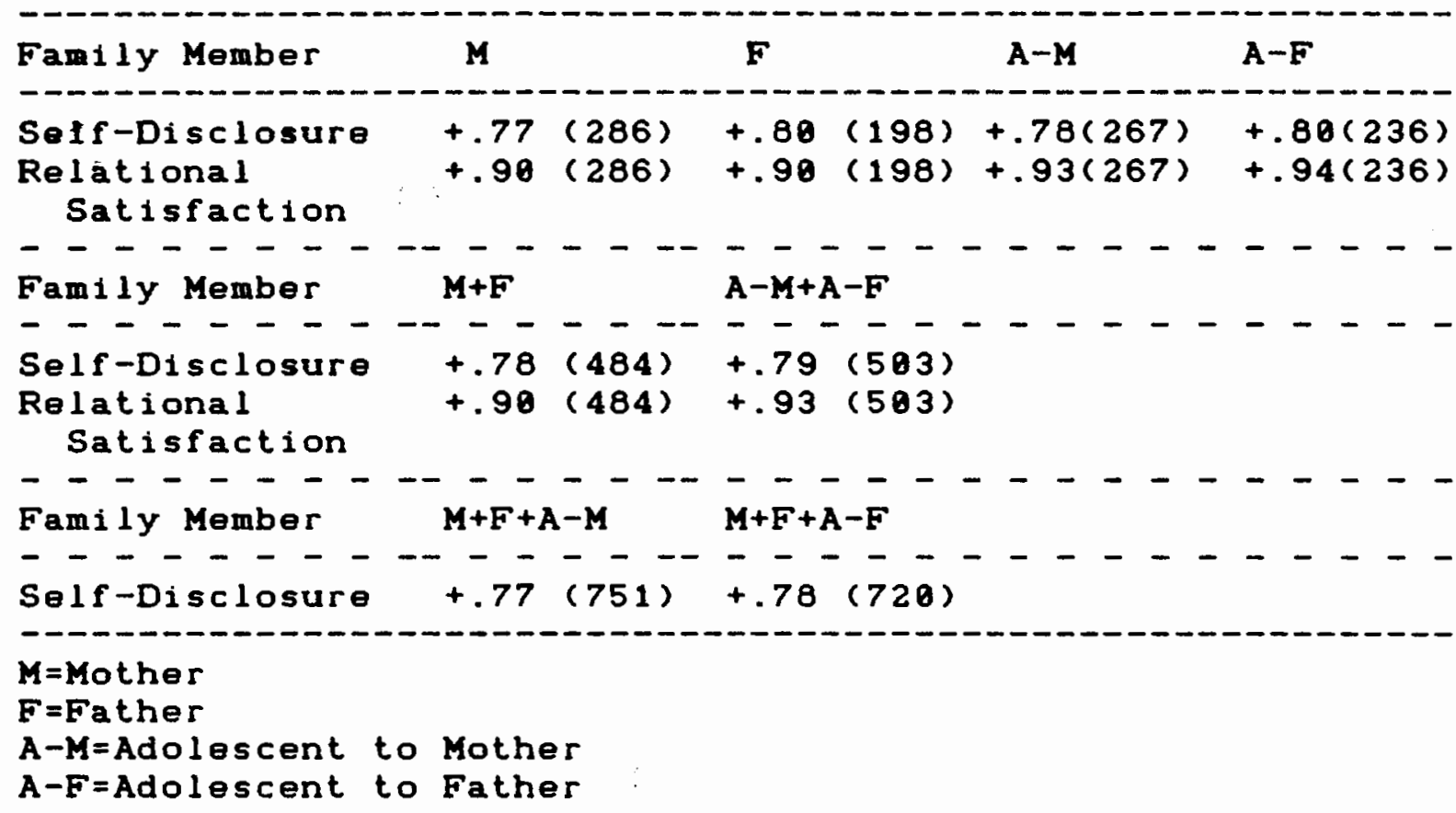


TABLE II

REL IABILITY SCORES BY FACTOR FOR THE SELF-DISCLOSURE INSTRUMENT

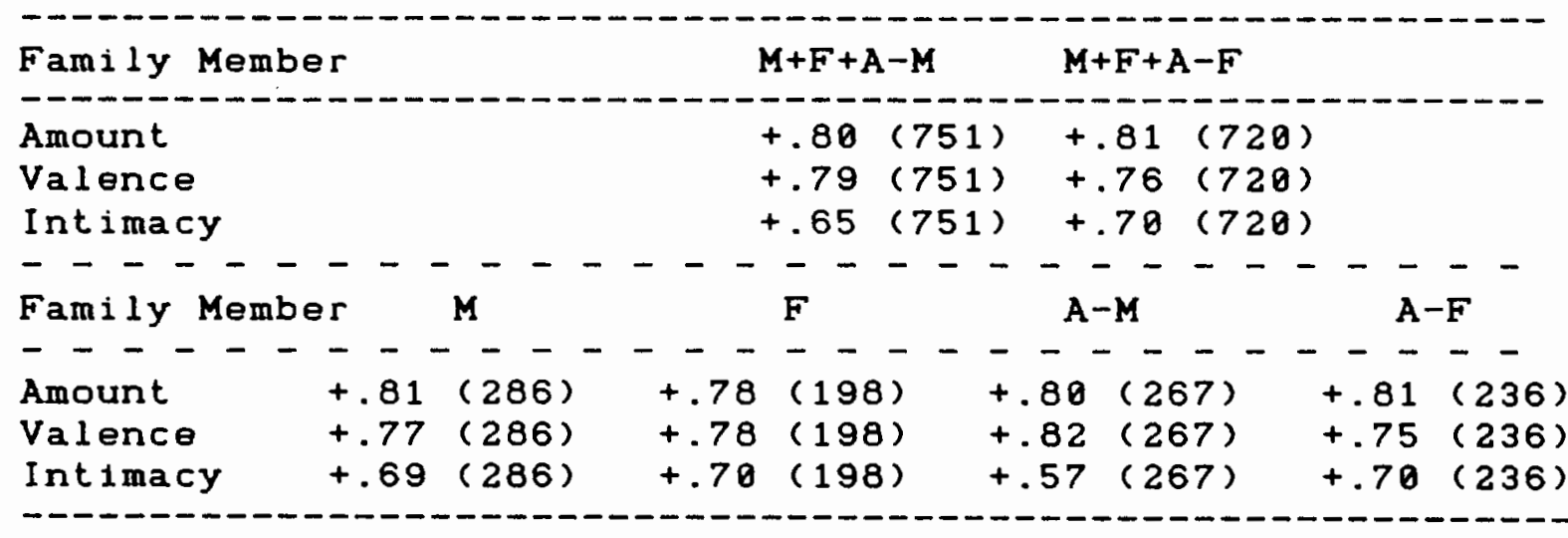

$M=$ Mother

A-M $=$ Adolescent to Mother

$F=F a t h e r$

$A-F=$ Adolescent to Father

ANALYSIS OF PRIMARY HYPOTHESES

In analyzing the results of the correlational

hypotheses of the present study, language conventions for describing strength of relationship developed by J.P.

Guilford (1956) were followed. Where appropriate, results corresponding to each main hypothesis are followed by parallel analyses by adolescent gender and by the grade level of the adolescents. All four hypotheses were directional, and the appropriate one-tailed tests of statistical significance were applied to " $r$ " and " $t$ " statistics. 


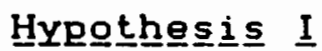

This hypothesis concerned the relationship between adolescent reports of SD with mothers and fathers and each parent's perception of adolescent SD for all families.

Results produced a low correlation, indicative of a definite but small relationship between adolescent reports of SD with their fathers and fathers' perception of SD $(r=+.22 ; p<.01)$ on 174 cases (see Table III). For SD reported by adolescents with their mothers, the correlation fell into the slight, almost negligible category $(r=+.19 ; p<.001)$ based on 259 cases (see Table IV).

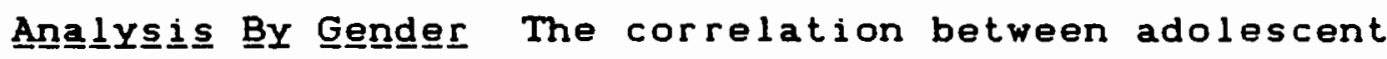
boys SD with their fathers and fathers' perception of that SD climbed into the moderate category $(r=+.47 ; p<.001)$ on 82 cases. For girls and their fathers, the results showed no relationship $(r=-.009 ; n s)$ on 92 cases. The relationship between adolescent girls SD with their mothers and mothers' perception of that $S D$ remained low $(r=+.29 ; p<.001)$ based on 48 cases. For boys and their mothers the correlation was negligible ( $r=+.08$;ns) based on 119 cases.

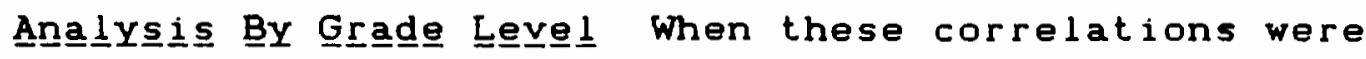
calculated by grade level, most of them showed no relationship. This was true of seventh graders' SD with fathers and their fathers' perception of $\operatorname{SD}(r=+.09 ; n s)$ on 
66 cases. Eighth graders had a higher correlation ( $r=+.32 ; p$ <. 01 ) based on 57 cases while the correlation between ninth graders and their fathers was again in the low range $(r=+.14 ; n s)$ on 46 cases. Results for adolescent SD with mothers also were significant at two age levels. For seventh graders the correlation was the highest yet still considered in the low range $(r=+.28 ; p<.01)$ on 100 cases. Correlations for eighth graders and their mothers were somewhat lower $(r=+.21 ; p<.05)$ on 86 cases, while ninth graders reported a non-significant relationship $(r=+.07$;ns $)$ on 62 cases.

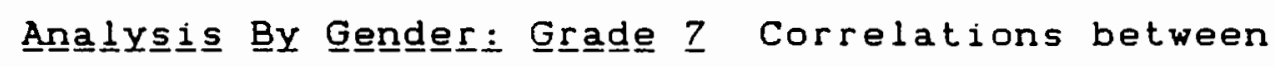
seventh grade girls' SD with their mothers and their mothers' perception of that SD were moderate $(r=+.45 ; p<$ 0.01 ) based on 47 cases. The remaining correlations among seventh graders showed no relationship. Boys and their mothers had a correlation of +.09 (ns) on 53 cases, boys and their fathers showed a correlation of +.18 (ns) on 36 cases and seventh grade girls and their fathers had the lowest correlation -.09 (ns) on 30 cases.

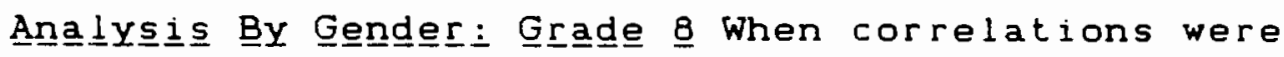
calculated for eighth graders, the only sample groups producing significant results were boys and their fathers and boys and their mothers. There was a high correlation between eighth grade boys SD with their fathers and their fathers' perception of $S D(r=+.70 ; p<.001)$ based on 27 
cases, signifying a marked relationship. Boys and their mothers produced a low correlation $(r=+.29 ;<.05)$ on 41 cases. The other correlations for this age group were non-significant. Girls and their fathers had a correlation of -.09 (ns) on 30 cases. The correlation for girls and their mothers was -.16 (ns) on 45 cases.

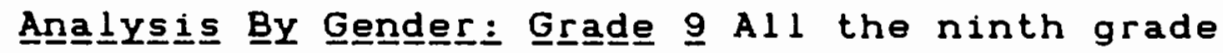
correlations were within the non-significant range. Girls and their mothers showed a correlation of +.18 (ns) on 38 cases. The correlation between boys and mothers was. -09 (ns) on 24 cases. For girls and fathers it was +.04 (ns) on 28 cases and boys and fathers +.23 (ns) on 18 cases.

\section{TABLE II I}

\section{RELATIONSHIP BETWEEN ADOLESCENT REPORTS OF SELF-DISCLOSURE TO FATHERS AND FATHERS' PERCEPTION OF SELF-DISCLOSURE FOR ALL FAMILIES}

\begin{tabular}{|c|c|c|c|c|}
\hline & & $\mathbf{r}$ & $\mathbf{p}$ & $\mathbf{n}$ \\
\hline A 11 & adolescents & +.22 & $<.01$ & 174 \\
\hline Boys & & +.47 & $<.001$ & 82 \\
\hline Gir & & -.009 & ns & 92 \\
\hline A 11 & 7 th graders & +.89 & ns & 66 \\
\hline A 11 & 8 th graders & +.32 & $<.01$ & 57 \\
\hline A 11 & 9 th graders & +.14 & ns & 46 \\
\hline 7 th & grade boys & +.18 & ns & 36 \\
\hline 8 th & grade boys & +.70 & $<.001$ & 27 \\
\hline 9 th & grade boys & +.23 & ns & 18 \\
\hline $7 \mathrm{th}$ & grade girls & -.09 & ns & 30 \\
\hline 8 th & grade girls & -.09 & ns & 30 \\
\hline 9 th & grade girls & +.04 & ns & 28 \\
\hline
\end{tabular}


TABLE IV

RELATIONSHIP BETWEEN ADOLESCENT REPORTS OF SELF-DISCLOSURE TO MOTHERS AND MOTHERS' PERCEPTION OF SELF-DISCLOSURE FOR ALL FAMILIES

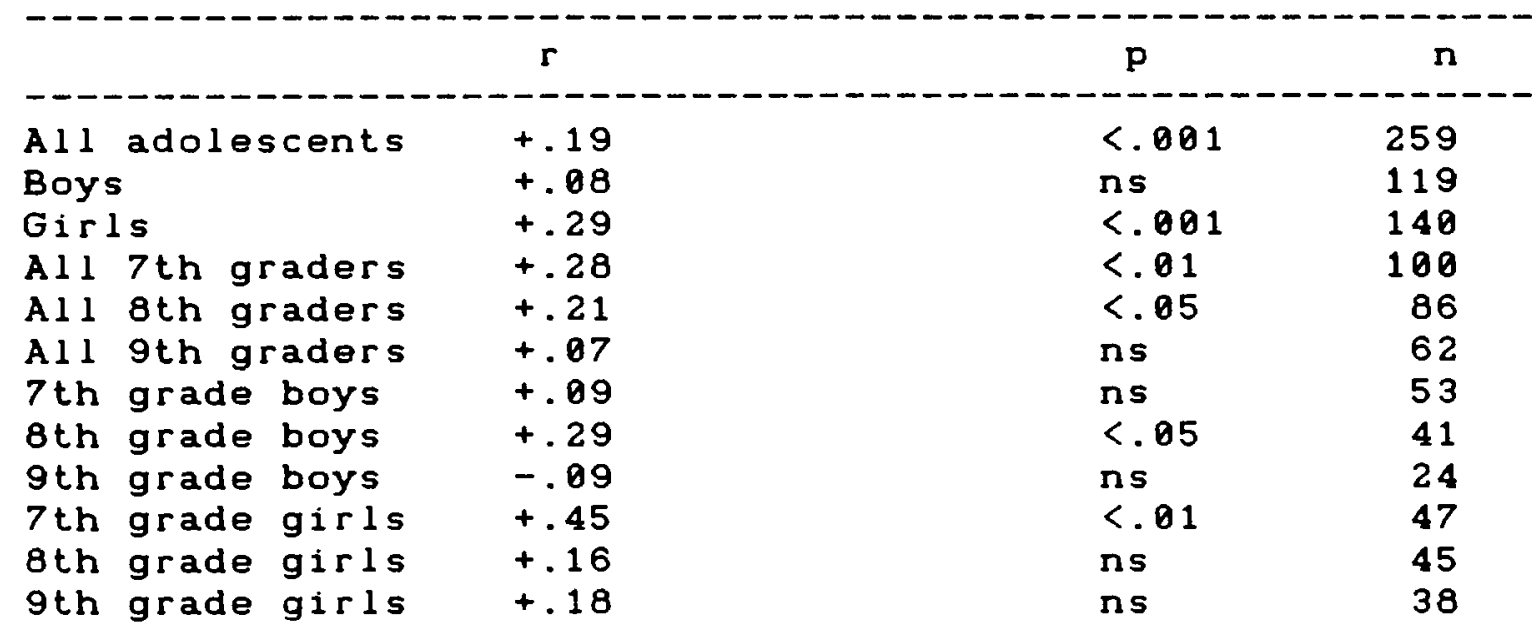

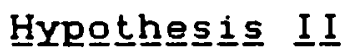

The relationship between adolescent reports of SD with their mothers and fathers and adolescent relational satisfaction (SI) with that parent for all families was addressed in this hypothesis. For adolescents and their mothers, there was a moderate correlation of +.46 ( $p<.001)$ on 275 cases (see Table V). The correlation was strikingly similar between adolescents and their fathers $(r=+.49 ; p<$ 0.001 ) on 254 cases (see Table VI).

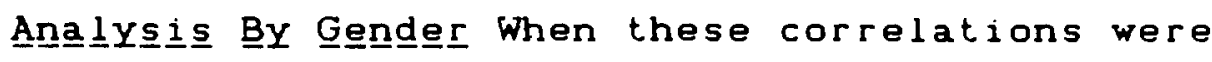
determined by gender, boys and girls reported almost an identical relationship between SD with their mother and relational SI. Boys and their mothers had a moderate 
correlation $(r=+.44 ; p<.001)$ on 125 cases. The correlation for girls and their mothers was only slightly higher $(r=+.48 ; p<.001)$ on 150 cases. Although the correlation produced by boys and girls between SD with their father and relational SI differed, it remained in the moderate category. For boys the correlation was $+.57(p<.001)$ on 122 cases, for girls it was $+.44(p<.001)$ based on 132 cases.

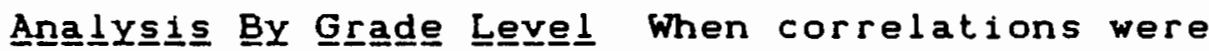
determined for adolescent reports of SD with their fathers and relational SI by grade level, seventh graders produced the lowest figures $(r=+.45 ; p<.001)$ on 102 cases. The correlation crept up slightly for ninth graders $(r=+.47 ; p<$ 0.001 ) on 81 cases. Eighth graders produced the highest correlation $(r=+.53 ; p<.801)$ on 62 cases. For adolescent reports of SD with their mothers and relational SI, the correlations were higher in all but one instance. Seventh graders registered correlations of $+.60(p<.001)$ on 187 cases; eighth graders had correlations of $+.57(p<.801)$ on 90 cases and ninth graders had scores of +.18 (ns) on 67 cases.

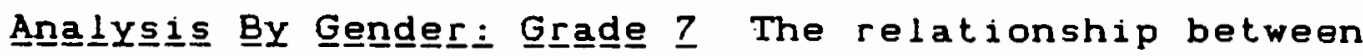
seventh grade boys' reports of SD with their fathers and relational SI was $+.53(p<.001)$ on 55 cases. For their mothers, the correlation jumped to $+.68(p<.001)$ on 55 
cases. When the correlation was calculated between seventh grade girls' reports of $S D$ with their fathers and relational SI, it dipped into the low category $(r=+.36 ; p<.01)$ on 47 cases. For seventh grade girls and their mothers, the correlation climbed back into the moderate range $(r=+.50 ; p$ (B. BD1) on 52 cases.

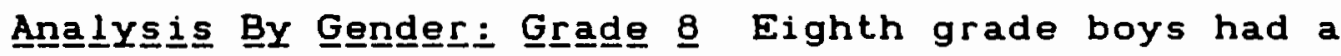
significantly higher relationship between reports of SD with their fathers and relational sI than with reports with their mothers. For fathers the correlation was $+.62(p<.001)$ on 40 cases, while for mothers it was $+.49(p<.801)$ on 42 cases. Girls produced higher correlations between reports of SD with their mothers and relational SI than with their fathers. Between girls and their mothers, the correlation was +.61 ( $p<.001$ ) on 48 cases, for girls and their fathers it was $+.42(p<.01)$ on 41 cases. All these correlations are in the moderate category.

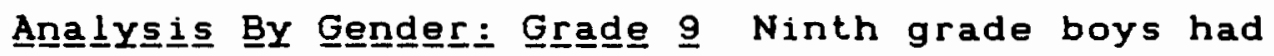
reports of higher correlations of SD with their fathers and relational SI than with their mothers. For boys and their fathers the correlation was $+.60(p<.001)$ on 26 cases. For boys and their mothers the correlation was non-significant $(r=+.0007 ; n s)$ on 27 cases. Ninth grade girls produced lower correlations of SD with their fathers and relational SI than boys reported. For ninth grade girls and their fathers the 
correlation was $+.48(\mathrm{p}<.01)$ on 36 cases. For ninth grade girls and their mothers it was $+.31(p<.05)$ on 40 cases.

\section{TABLE V}

RELATIONSHIP BETWEEN ADOLESCENT REPORTS OF SELF-DISCLOSURE AND ADOLESCENT RELATIONAL SATISFACTION TO MOTHERS FOR ALL FAMILIES

\begin{tabular}{|c|c|c|c|c|}
\hline & & $\mathbf{r}$ & $\mathrm{p}$ & $\mathbf{n}$ \\
\hline$A 11$ & adolescents & +.46 & $<.001$ & 275 \\
\hline Boy & & +.44 & $<.001$ & 125 \\
\hline Gir & & +.48 & $<.001$ & 158 \\
\hline A 11 & 7 th graders & +.60 & $<.001$ & 107 \\
\hline A 11 & 8th graders & +.57 & $<.001$ & 90 \\
\hline A 11 & 9 th graders & +.18 & ns & 67 \\
\hline $7 \mathrm{th}$ & grade boys & +.68 & $<.081$ & 55 \\
\hline $8 \mathrm{th}$ & grade boys & +.49 & $<.001$ & 42 \\
\hline $9 t h$ & grade boys & +.0007 & ns & 27 \\
\hline $7 \mathrm{th}$ & grade girls & +.58 & $<.081$ & 52 \\
\hline $8 \mathrm{th}$ & grade girls & +.61 & $<.001$ & 48 \\
\hline 9 th & grade girls & +.31 & $<.05$ & 40 \\
\hline
\end{tabular}

TABLE VI

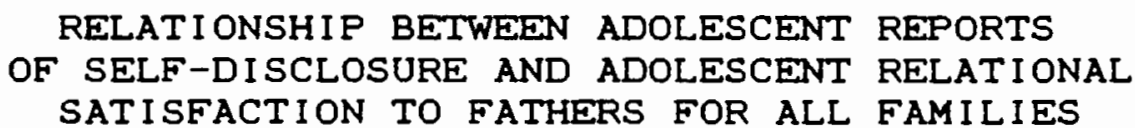
SATISFACTION TO FATHERS FOR ALL FAMILIES

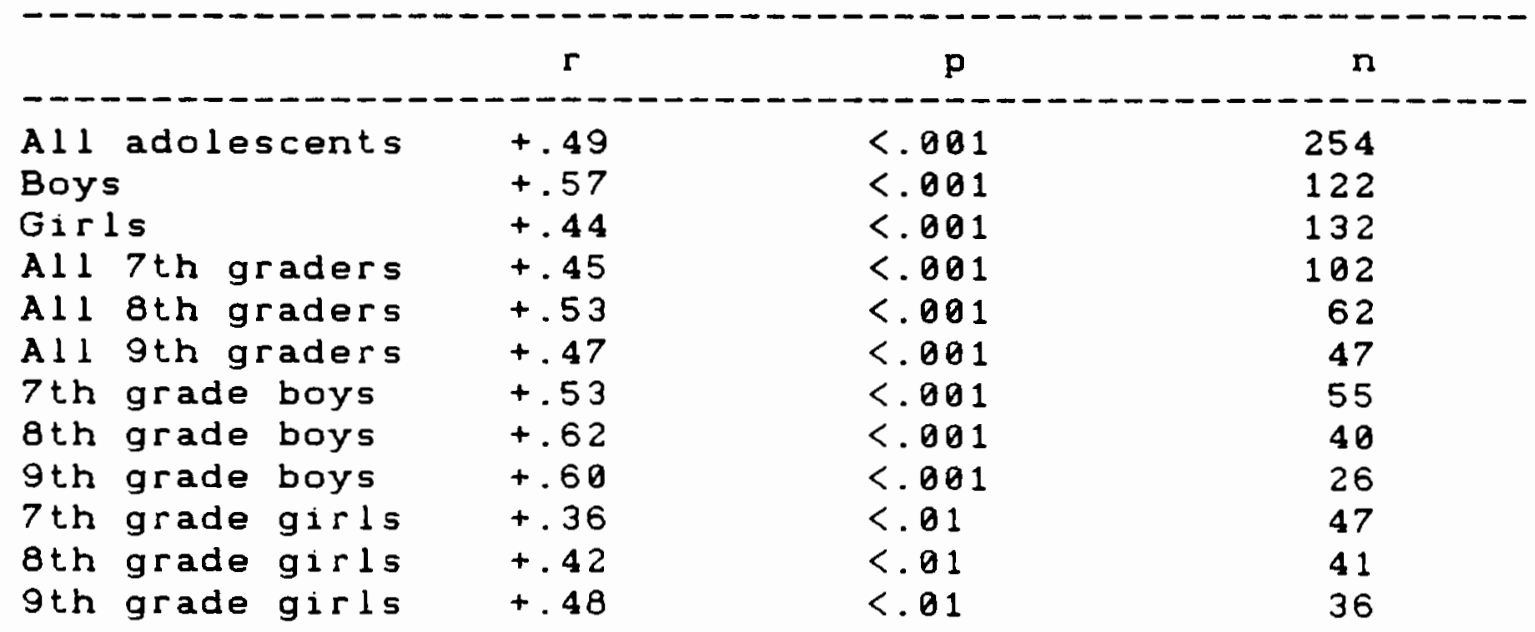


HYRothhesis $1 \underline{1} \underline{I}$

This hypothesis concerned the relationship between adolescent reports of SD with each parent and that parents' expressed SI with their adolescent for all families. The correlations were similar for both parents and stayed in the low range, indicative of a definite but small relationship. For adolescents and mothers the correlation was +.24 ( $p$ (.001) on 259 cases (see Table VII), for adolescents and their fathers it was $+.23(p<.001)$ on 174 cases (see Table VII I .

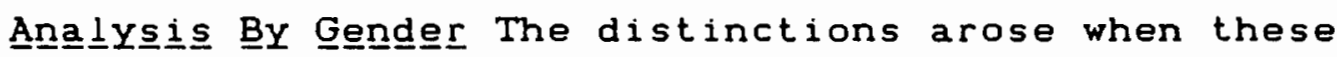
calculations were performed by gender. There was no relationship between boys' SD and their mothers' SI $(r=+.08 ; n s)$ on 119 cases. For mothers and daughters, a low correlation was shown $(r=+.36 ; p<.001)$ based on 140 cases.

When these correlations were computed for adolescents and their fathers, there was a small relationship found between boys' SD and their fathers' SI $(r=+.36 ; p<.001)$ on 82 cases, while the correlation was non-significant for girls and their fathers ( $r=+.14 ; n s)$ based on 92 cases.

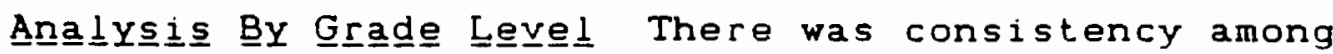
adolescent reports of SD to their mother by grade level and their mothers' SI with their adolescent daughters. All findings indicated no relationship. For seventh graders the 
correlation was non-significant +.16 (ns) on 100 cases.

Eighth graders produced similar findings +.18 (ns) on 86 cases as did ninth graders -.04 (ns) on 62 cases.

Turning to fathers, there was no relationship between seventh grade reports of SD and fathers' SI ( $r=+.10 ; n s)$ based on 66 cases, and a small relationship shown between eighth and ninth grade reports of SD and fathers' SI. For eighth graders the correlation was $+.24(p<.05)$ on 57 cases, while for ninth graders it was $+.27(p<.05)$ based on 46 cases.

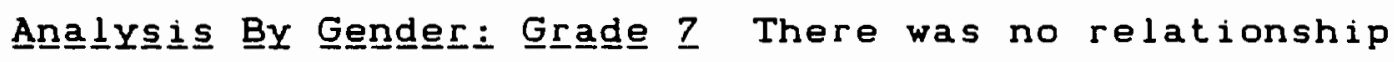
found between seventh grade boys' SD with their mothers and fathers and that parents' SI with their adolescents. For boys and mothers the correlation was +.17 (ns) on 53 cases; seventh grade boys and their fathers produced a correlation of +.85 (ns) based on 36 cases.

The same pattern held for seventh grade girls and their mothers $(r=+.14 ; n s)$ on 47 cases and for girls and their fathers $(r=+.20 ; n s)$ based on 30 cases.

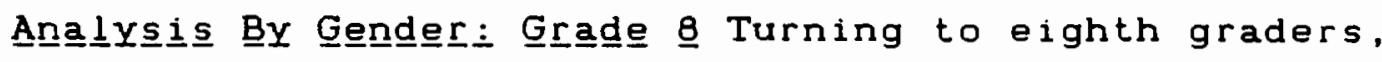
boys and their mothers showed no relationship ( $r=-.04 ; n s)$ on 41 cases, for eighth grade boys and their fathers, a moderate correlation was determined, evident of a substantial relationship $(r=+.47 ; p<.01)$ based on 27 cases.

Eighth grade girls and their mothers showed a low correlation, indicative of a small relationship ( $r=+.35 ; p<$ 
0.01 ) based on 45 cases. For eighth grade girls and their

fathers, there was no relationship ( $r=-.007$;ns) on 30 cases.

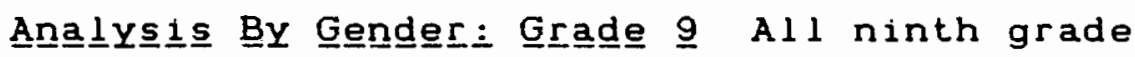
correlations were non-significant. Ninth grade boys and mothers had a correlation of +.86 ( $n s$ ) based on 24 cases. The correlation for boys and fathers was somewhat higher but still remained non-significant $(r=+.25 ; n s)$ on 18 cases. For ninth grade girls and mothers, the correlation was $r=-.15$ (ns) on 38 cases, and girls and fathers registered $r=+.27$ (ns) on 28 cases.

\section{TABLE VII}

RELATIONSHIP BETWEEN ADOLESCENT REPORTS OF SELF-DISCLOSURE TO MOTHERS AND MOTHERS' RELATIONAL SATISFACTION WITH ADOLESCENTS FOR ALL FAMILIES

$\begin{array}{llll} & & 0 & n \\ \text { All adolescents } & +.24 & +.001 & 259 \\ \text { Boys } & +.88 & \text { ns } & 119 \\ \text { Girls } & +.36 & \text { ns } & 140 \\ \text { All } 7 \text { th graders } & +.16 & n s & 100 \\ \text { All } 8 \text { th graders } & +.18 & \text { ns } & 86 \\ \text { All } 9 \text { th graders } & -.04 & \text { ns } & 62 \\ 7 \text { th grade boys } & +.17 & \text { ns } & 53 \\ 8 \text { th grade boys } & -.04 & \text { ns } & 24 \\ 9 \text { th grade boys } & +.06 & \text { ns } & 47 \\ 7 \text { th grade girls } & +.14 & <.01 & 45 \\ 8 \text { th grade girls } & +.35 & \text { ns } & 38 \\ 9 \text { th grade girls } & -.15 & & \end{array}$


TABLE VI I I

\section{RELATIONSHIP BETWEEN ADOLESCENT SELF-DISCLOSURE TO FATHERS AND FATHERS' RELATIONAL SATISFACTION WITH ADOLESCENTS FOR ALL FAMILIES}

\begin{tabular}{|c|c|c|c|c|c|}
\hline & & & $r$ & $p$ & $n$ \\
\hline$A \perp 1$ & adole & escents & +.23 & $<.001$ & 174 \\
\hline Boys & & & +.36 & $<.001$ & 82 \\
\hline Girl & & & +.14 & ns & 92 \\
\hline$A \perp 1$ & 7 th $\mathrm{g}$ & graders & +.10 & ns & 66 \\
\hline$A 11$ & 8 th $\mathrm{g}$ & graders & +.24 & $<.05$ & 57 \\
\hline$A \perp 1$ & $9 \operatorname{th} g$ & graders & +.27 & $<.05$ & 46 \\
\hline 7 th & grade & e boys & +.05 & ns & 36 \\
\hline $8 t h$ & grade & e boys & +.47 & $<.01$ & 27 \\
\hline 9 th & grade & e boys & +.25 & ns & 18 \\
\hline 7 th & grade & e girls & +.20 & ns & 30 \\
\hline 8 th & grade & e girls & -.007 & ns & 30 \\
\hline $9 \mathrm{th}$ & grade & e girls & +.27 & ns & 28 \\
\hline
\end{tabular}

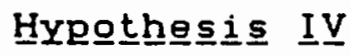

Contrary to prediction, fathers reported higher SD from their adolescents than mothers $(t=2.58 ; p<.01)$ based on 320 cases from mothers and 220 cases from fathers (see Table IX) for all families. This result comprised the first statistically significant finding that contradicted an hypothesis.

TABLE IX

COMPARISON OF MOTHERS' VERSUS FATHERS' RECEIPT OF SELF-DISCLOSURE FOR ALL FAMILIES

\begin{tabular}{|c|c|c|c|c|c|c|}
\hline & $\mathbf{M}$ & s.d. & $5 . \theta$. & d. f. & $t$ & $\mathrm{p}$ \\
\hline \multirow[t]{2}{*}{ Mothers } & 69.43 & 14.27 & 0.80 & & & \\
\hline & & & & 538 & 2.58 & $<.01$ \\
\hline
\end{tabular}

Fathers

$$
\begin{array}{llll}
72.61 & 13.79 & 0.93
\end{array}
$$




\section{FOLLOW-UP ANALYSES}

With the large data base in hand and given the cumulative results of the four hypotheses discussed above, several posst hoㅡㅁㅡ analyses seemed to be in order. These all fell into the category of a postérígri and opportunistic probes of the data and were treated with corresponding protocols; víz, two-tailed tests of statistical significance.

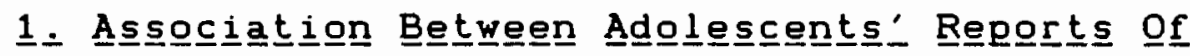

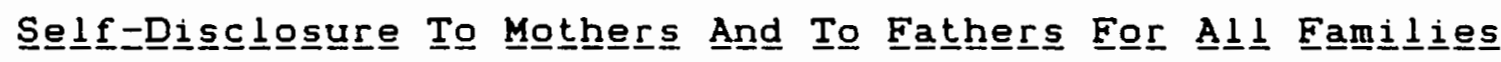
These analyses focused on the relationship between adolescent reports of self-disclosure (SD) to their mothers and reports of SD to their fathers for all families within this study. The data produced a moderate correlation, evident of a substantial relationship $(r=+.46 ; p<.001)$ for 254 cases (see Table X). For girls, this correlation was slightly higher than their male counterparts. Girls produced a correlation of $+.50(p<.801)$ on 132 cases, while for boys the correlation was $+.43(\mathrm{p}<.001)$ on 122 cases. Both correlations are considered moderate.

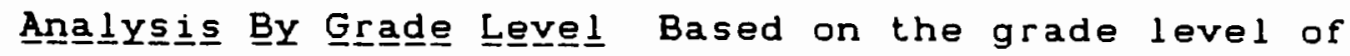
adolescents, seventh graders registered the highest correlation $(r=+.52 ; p<.001)$ for 102 cases. The correlation for eighth and ninth graders on SD reports to their mothers 
and to their fathers was exactly the same $(r=+.42 ; p<$ 0.001 ). These are moderate correlations. There were 81 eighth graders and 62 ninth graders.

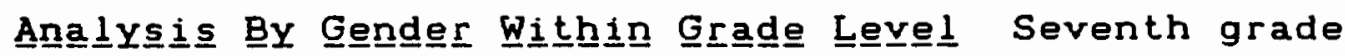
girls produced higher correlations than seventh grade boys. For girls, the correlation approached the high range $(r=+.63 ; p<.001)$, with 47 cases. For boys the correlation stayed in the moderate area $(r=+.47 ; p<.001)$ with 55 cases. Eighth grade boys produced a correlation of $+.58(\mathrm{p}<.001)$ on 40 cases when SD reports to their mothers and fathers were tabulated. For eighth grade girls, the correlation was $+.32(p<.05)$ on 41 cases. The correlation for ninth grade boys was $+.26(p<.05)$ on 26 cases. Ninth grade girls produced a correlation of $+.51(p<.01)$ on 36 cases.

TABLE $X$

RELATIONSHIP BETWEEN ADOLESCENT REPORTS OF SELF-DISCLOSURE TO MOTHERS AND TO FATHERS FOR ALL FAMILIES

\begin{tabular}{|c|c|c|c|c|}
\hline & & $r$ & $\mathbf{p}$ & $\mathbf{n}$ \\
\hline$A 11$ & adolescents & +.46 & $<.001$ & 254 \\
\hline Girl & & +.50 & $<.001$ & 132 \\
\hline Boys & & +.43 & $<.001$ & 122 \\
\hline A 11 & 7 th graders & +.52 & $<.001$ & 102 \\
\hline$A 11$ & 8th graders & +.42 & $<.001$ & 81 \\
\hline A 11 & 9 th graders & +.42 & $<.001$ & 62 \\
\hline 7 th & grade boys & +.47 & $<.001$ & 55 \\
\hline 8 th & grade boys & +.58 & $<.001$ & 48 \\
\hline $9 \mathrm{th}$ & grade boys & +.26 & $<.05$ & 26 \\
\hline $7 \mathrm{th}$ & grade girls & +.63 & $<.001$ & 47 \\
\hline 8 th & grade girls & +.32 & $<.85$ & 41 \\
\hline $9 \operatorname{th}$ & grade girls & +.51 & $<.01$ & 36 \\
\hline
\end{tabular}




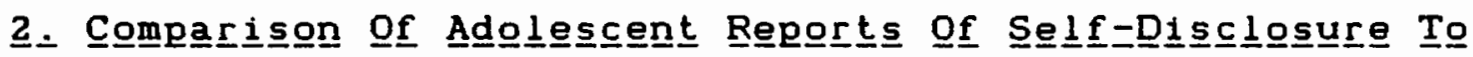

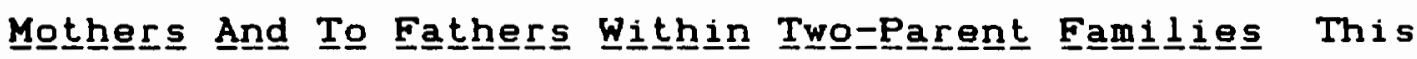
analysis compared data from adolescents who reported that they lived with both parents. Adolescent SD was higher for fathers than mothers $(t=4.84 ; p<.001$ ) on 201 cases (see Table XI). This is a very important result because it substantiated findings contradicting hypothesis IV, which found that fathers reported receiving more SD from adolescents than mothers.

Anaㅁyㅗㅛㅁㅗ By Gender When these calculations were done by gender, the results were similar. Girls in two-parent families indicated higher SD to their fathers than their mothers $(t=5.35 ; p<.001)$ based on 107 cases. The SD correlations for boys living in two-parent families also favored the fathers, however here the results were nonsignificant $(t=1.37$;ns $)$ based on 94 cases. 
TABLE XI

COMPARISON OF ADOLESCENT REPORTS OF SELF-DISCLOSURE TO MOTHERS VERSUS FATHERS WITHIN TWO-PARENT FAMILIES

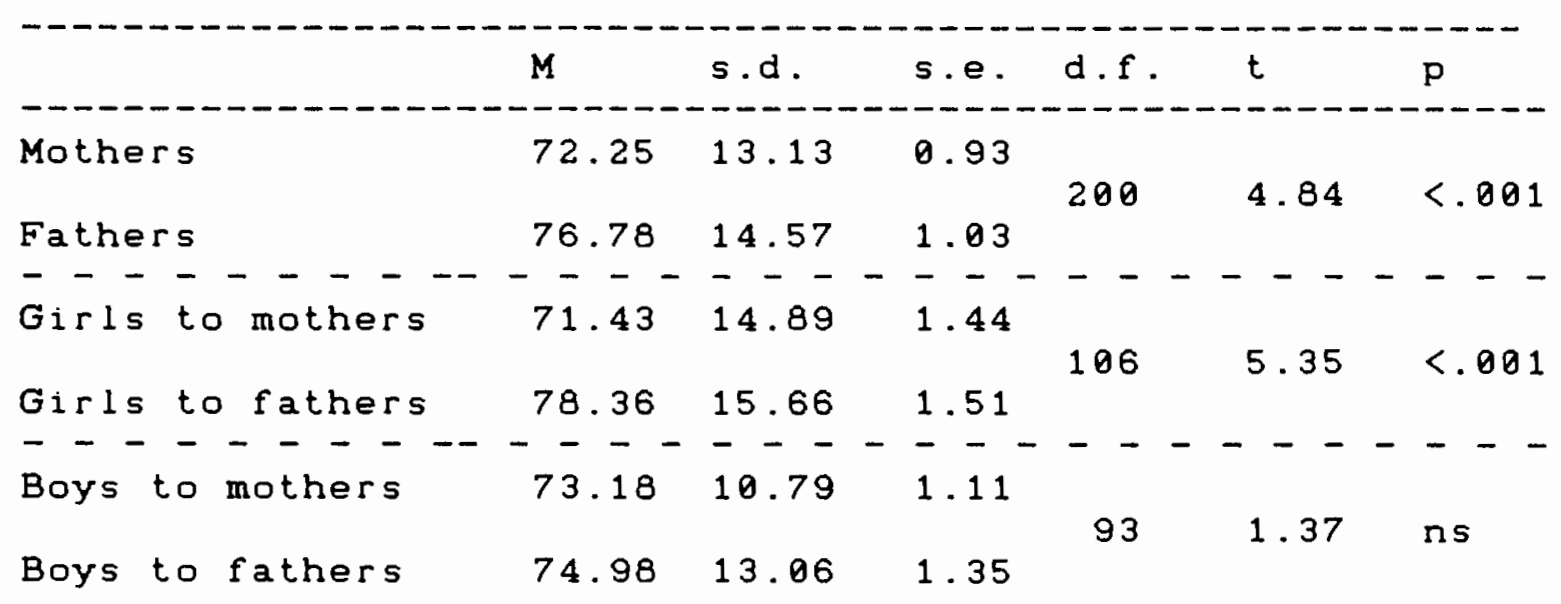

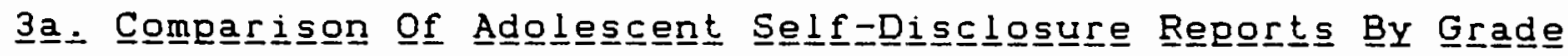

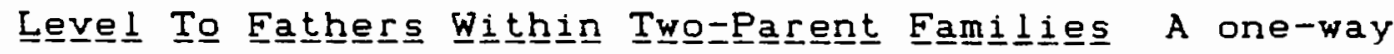
analysis of variance was computed for seventh, eighth and ninth grade levels on adolescent SD to fathers in two-parent families (see Table XII). The between groups F ratio was 4.77, and the three group mean correlations were 73.09 , 77.89 and 81.11 , respectively, for seventh, eighth and ninth graders. The mean difference between seventh and ninth graders was statistically significant ( $p<.01)$, using the LSD procedure. 
TABLE XI I

COMPARISON OF ADOLESCENT REPORTS OF SELF-DISCLOSURE BY GRADE LEVEL WITH FATHERS WITHIN TWO-PARENT FAMILIES

\begin{tabular}{|c|c|c|c|c|c|}
\hline Source & d. f . & $\begin{array}{l}\text { Sum of } \\
\text { Squares }\end{array}$ & $\begin{array}{l}\text { Mean } \\
\text { Squares }\end{array}$ & Fratio & F prob. \\
\hline Between groups & 2 & 1908.18 & 954.09 & 4.77 & $<.01$ \\
\hline $\begin{array}{l}\text { Linear term } \\
\text { (unweighted) }\end{array}$ & 1 & 1854.10 & 1854.10 & 9.26 & $<.85$ \\
\hline $\begin{array}{l}\text { Deviation from } \\
\text { linear }\end{array}$ & 1 & 0.00 & 0.00 & 0.00 & ns \\
\hline Within groups & 189 & 37832.29 & 200.17 & & \\
\hline Tota 1 & 191 & 39746.48 & & & \\
\hline
\end{tabular}

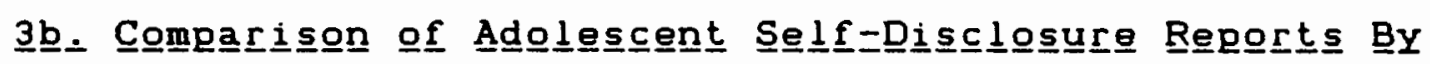

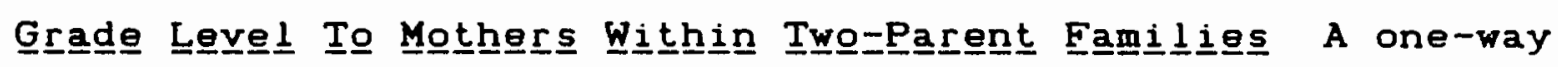
analysis of variance was computed for seventh, eighth and ninth graders on adolescent SD to mothers in two-parent families (see Table XIII). The between groups F ratio was 3.30 , and the three group mean correlations were 69.18, 74.03 and 74.16 , respectively, for seventh, eighth and ninth graders. Once again the mean difference between seventh and ninth graders was statistically significant ( $p<.05$ ), using the LSD procedure. 
TABLE XI I I

COMPARISON OF ADOLESCENT REPORTS OF SELF-DISCLOSURE BY GRADE LEVEL WITH MOTHERS WITHIN TWO-PARENT FAMILIES

\begin{tabular}{|c|c|c|c|c|c|}
\hline Source & d. f. & $\begin{array}{l}\text { Sum of } \\
\text { Squares }\end{array}$ & $\begin{array}{l}\text { Mean } \\
\text { Squares }\end{array}$ & Fratio & F prob. \\
\hline Between groups & 2 & 1143.72 & 571.86 & 3.30 & $<.05$ \\
\hline $\begin{array}{l}\text { Linear term } \\
\text { (unweighted) }\end{array}$ & 1 & 718.45 & 718.45 & 4.14 & $<.05$ \\
\hline $\begin{array}{l}\text { Deviation from } \\
\text { linear }\end{array}$ & 1 & 241.09 & 241.09 & 1.39 & ns \\
\hline Within groups & 193 & 33488.11 & 173.51 & & \\
\hline rotal & 195 & 34631.82 & & & \\
\hline
\end{tabular}

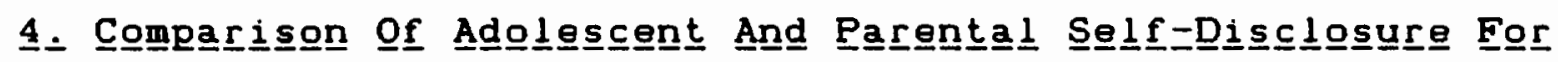

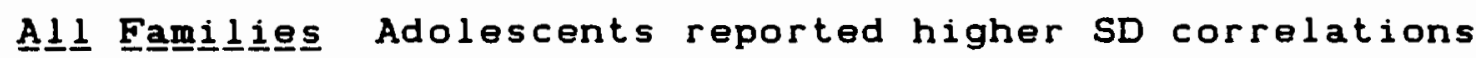
for their fathers than their mothers for all families $(t=5.35 ; p<.001)$ on 254 cases (see Table XIV). This finding was consistent throughout this study.

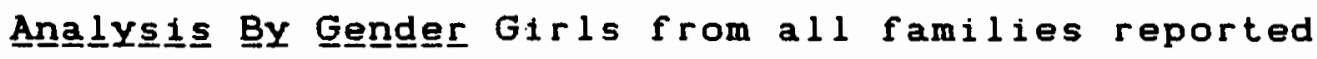
higher SD to their fathers $(t=2.39 ; p<.05)$ on 122 cases, as did boys $(t=5.08 ; p<.001)$ on 132 cases. 
COMPARISON OF ADOLESCENT REPORTS OF SELF-DISCLOSURE WITH MOTHERS VERSUS FATHERS FOR ALL FAMILIES

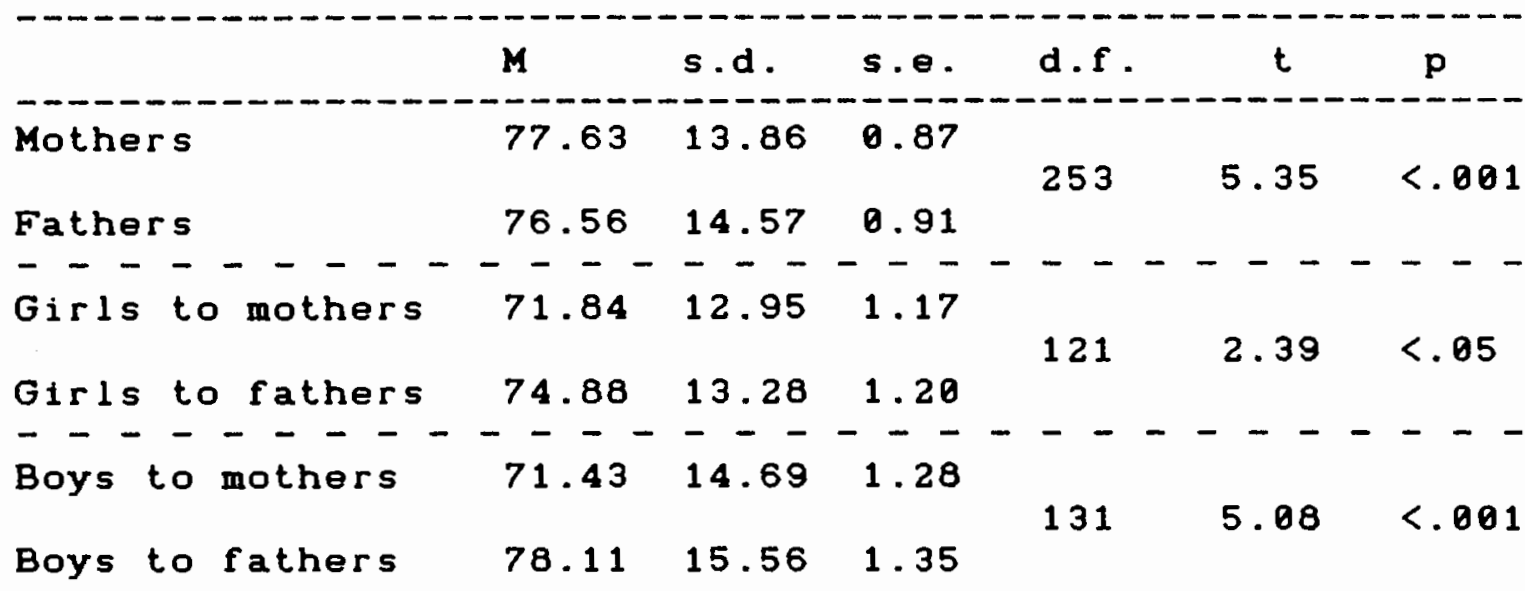

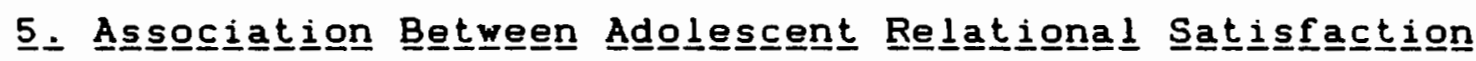

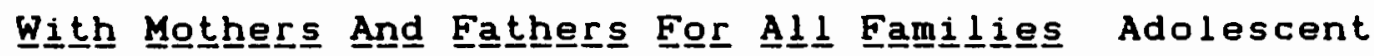
reports of relational satisfaction (SI) with their mothers and their fathers were examined, resulting in a moderate correlation of $+.52(p<.001$ ) on 254 cases (see Table XV). Boys produced a higher correlation $+.57 ;(p<.001)$ than girls $+.49 ; p<.001)$. There were 122 boys and 132 girls.

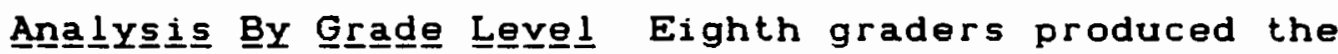
highest correlation, $+.59(\mathrm{p}<.801)$ on 81 cases. Seventh graders produced a correlation of $+.56(p<.001)$ on 102 cases. For ninth graders the correlation was the lowest, $+.43(\mathrm{p}<.001)$ on 62 cases. All these correlations are within the moderate range and indicate a substantial relationship. 


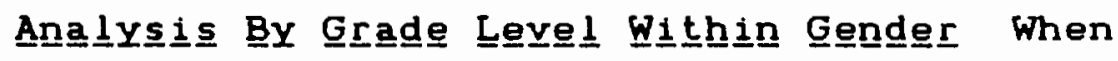
correlations were determined by grade level and by gender, seventh grade girls produced a high correlation, +.61 ( $p<$ 0.001 ) on 47 cases. For seventh grade boys, the correlation was +.52 ( $p<.001)$ on 55 cases. These correlations are whin the moderate category. Eighth grade boys produced a correlation that reached the high category, indicative of a marked relationship $(r=+.75 ; p<.001)$ on 40 cases. For eighth grade girls, the correlation remained in the moderate category $(r=+.46 ; p<.001)$ on 41 cases. Ninth grade boys and girls reported similar correlations. For boys the correlation was +.41 $(p<.05)$ on 26 cases, while for girls it was $+.44(p<.01)$ on 36 cases.

\section{TABLE XV}

RELATIONSHIP BETWEEN ADOLESCENT RELATIONAL SATISFACTION WITH MOTHERS AND FATHERS FOR ALL FAMILIES

\begin{tabular}{|c|c|c|c|}
\hline & $\mathbf{r}$ & $\mathbf{p}$ & $\mathbf{n}$ \\
\hline Al1 adolescents & +.52 & $<.001$ & 254 \\
\hline Girls & +.49 & $<.001$ & 132 \\
\hline Boys & +.57 & $<.001$ & 122 \\
\hline All 7 th graders & +.56 & $<.001$ & 102 \\
\hline All 8th graders & +.59 & $<.001$ & 81 \\
\hline All 9th graders & +.43 & $<.001$ & 62 \\
\hline 7 th grade boys & +.52 & $<.001$ & 55 \\
\hline 8 th grade boys & +.75 & $<.001$ & 40 \\
\hline 9th grade boys & +.41 & $<.85$ & 26 \\
\hline 7 th grade girls & +.61 & $<.001$ & 47 \\
\hline 8th grade girls & +.46 & $<.001$ & 41 \\
\hline 9th grade girls & +.44 & $<.01$ & 36 \\
\hline
\end{tabular}




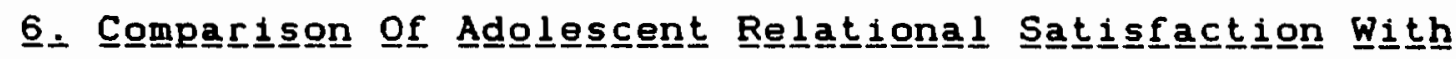

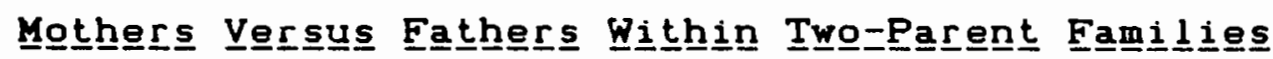

Adolescents in two-parent families reported more SI with their mothers than fathers, however their differences were non-significant $(t=0.10 ; n s)$ on 201 cases.

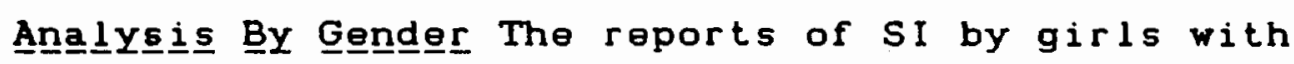
their mothers as compared with their fathers were all nonsignificant (see Table XVI). Girls in two-parent families had a higher SI with fathers than mothers $(t=0.23 ; n s)$ on 94 cases. Although boys in two-parent families indicated more satisfaction with their mothers, the results were nonsignificant $(t=0.35 ; n s)$ on 107 cases.

\section{TABLE XVI}

COMPARISON OF ADOLESCENT RELATIONAL SATISFACTION WITH MOTHERS VERSUS FATHERS WITHIN TWO-PARENT FAMILIES

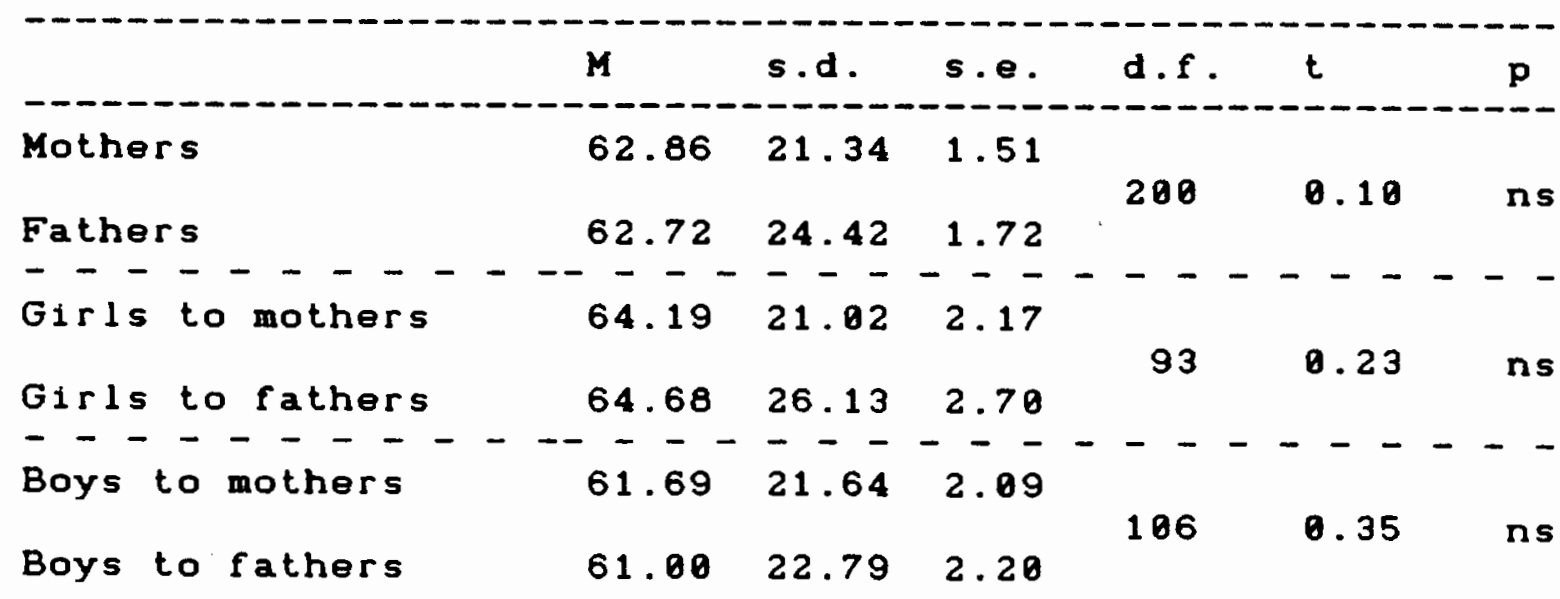

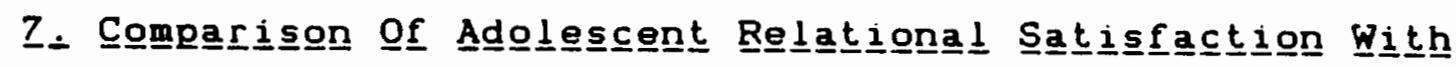

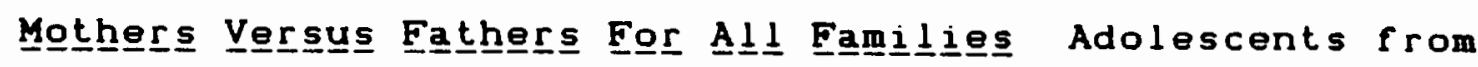


all families were more satisfied with their mothers than fathers, but again, as in the case of adolescents living in two-parent families, the results were non-significant $(t=0.42 ; n s)$ on 253 cases (see Table XVII).

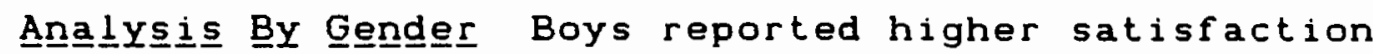
with their fathers than mothers ( $t=0.20 ; n s)$, while girls were more satisfied with their mothers $(t=0.39 ; n s)$.

\section{TABLE XVII}

COMPARISON OF ADOLESCENT RELATIONAL SATISFACTION WITH MOTHERS VERSUS FATHERS FOR ALL FAMILIES

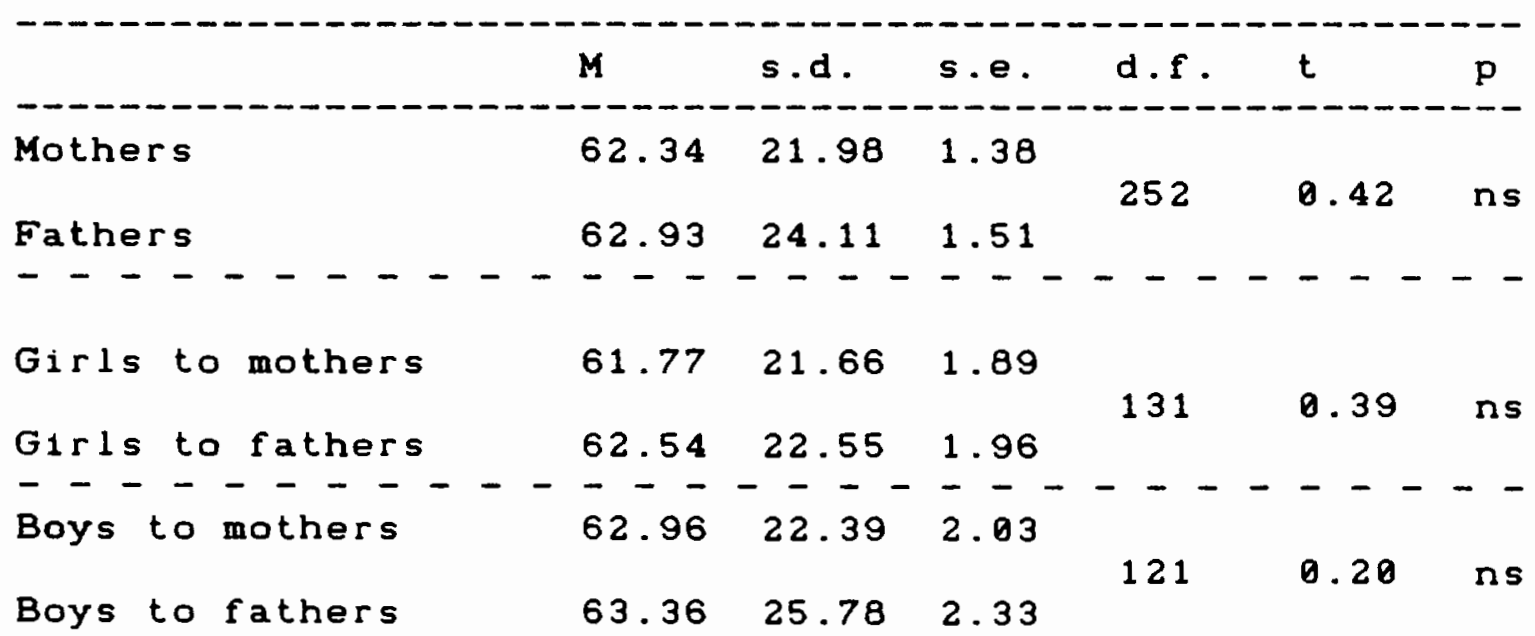

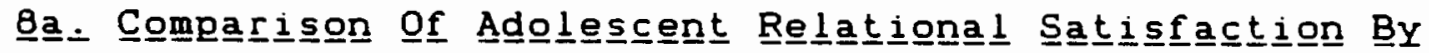

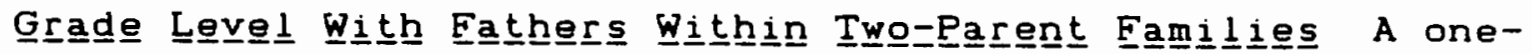
way analysis of variance was completed for seventh, eighth and ninth grade levels on adolescent SD to fathers in twoparent families (see Table XVIII). The between groups F ratio was 1.62 (ns) and the three group means were 58.56 . 
65.63 and 62.87 . respectively, for seventh, eighth and ninth graders. The mean difference between seventh and ninth graders was not statistically significant (ns) using the LSD procedure.

TABLE XVI I I

COMPARISON OF ADOLESCENT RELATIONAL SATISFACTION BY GRADE LEVEL WITH FATHERS WITHIN TWO-PARENT FAMILIES

$\begin{array}{lccccc}\text { Source } & \text { d.f. } & \begin{array}{l}\text { Sum of } \\ \text { Squares }\end{array} & \begin{array}{l}\text { Mean } \\ \text { Squares }\end{array} & \text { F ratio } & \text { Frob. } \\ \text { Between groups } & 2 & 1860.18 & 930.09 & 1.62 & \text { ns } \\ \begin{array}{l}\text { Linear term } \\ \text { (unweighted) }\end{array} & 1 & 533.54 & 533.54 & 0.93 & \text { ns } \\ \begin{array}{l}\text { Deviation } \\ \text { from linear }\end{array} & 1 & 1822.22 & 1822.22 & 1.78 & \text { ns } \\ \text { Within groups } & 189 & 188318.56 & 573.11 & & \\ \text { Total } & 191 & 1106178.74 & & \end{array}$

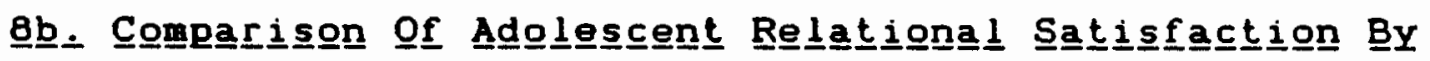

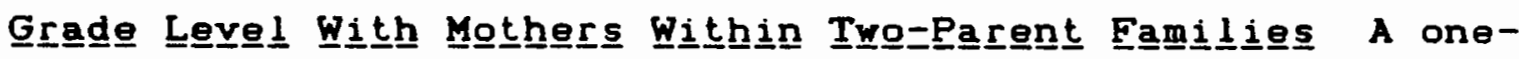
way analysis of variance was completed for seventh, eighth and ninth grade levels on adolescent SD to mothers in twoparent families (see Table XVIV). The between groups F ratio was 2.32 (ns) and the three group means were 59.55, 67.06 and 62.44, respectively, for seventh, eighth and ninth graders. The mean difference between seventh and ninth graders was statistically significant $(p<.05)$ using the LSD procedure. 
TABLE XVIV

COMPARISON OF ADOLESCENT RELATIONAL SATISFACTION BY GRADE LEVEL WITH MOTHERS WITHIN ALL FAMILIES

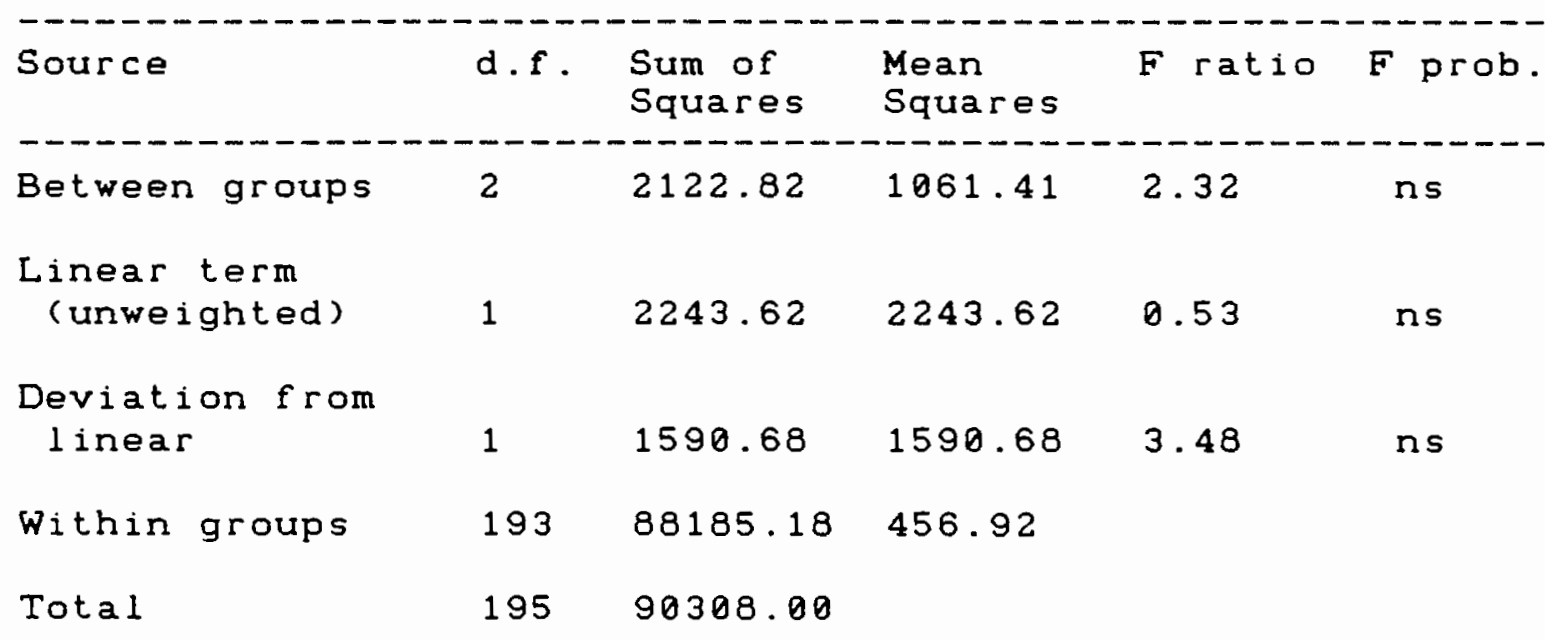

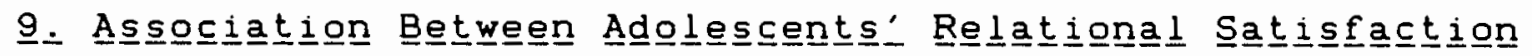

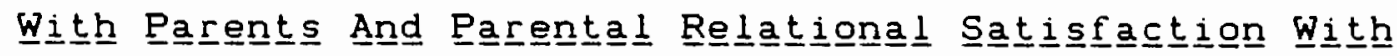
A mothers and fathers and each parents' SI with their adolescents for all families was addressed in this hypothesis. For adolescents and their mothers, the correlation was low, indicating a definite but small relationship $(r=+.26 ; p<.001)$ based on 259 cases (see Table $X X)$. Although the correlation was somewhat higher between adolescents and fathers, it still remained in the low category $(r=+.38 ; p<.9 B 1)$ on 174 cases (sge Table XXI).

Analysis By Gender There was very little distinction between boy and girl reports of SI with their mothers and their fathers' reports of SI for all families. Both correlations were low. For boys and their mothers, the 
correlation was $+.22(p<.01)$ on 119 cases, for girls and their mothers it was $+.30(p<.001)$ on 140 cases. When SI reports were correlated for fathers and adolescents by gender, there was a sharp distinction. Girls had a low correlation $(r=+.29 ; p<.01)$ on 92 cases, while the correlation for boys was moderate, evident of a substantial relationship $(r=+.46 ; p<.001)$ based on 82 cases.

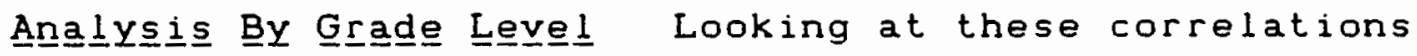
by grade level, there was consistency among the findings, with most staying in the low range. For seventh graders and their mothers the correlation was $+.39(p<0.001)$ on 100 cases. The correlation for seventh graders and fathers was $+.35(p<.01)$ on 66 cases. Mothers and eighth graders had a correlation of $+.31(p<.01)$ on 86 cases, fathers and eighth graders produced a slightly higher correlation, +.39 $(p<.001)$ on 57 cases. Ninth graders and their mothers showed no relationship when SI reports were correlated ( $r=+.09 ; n s)$ on 62 cases. For ninth graders and their fathers, the correlation reached the moderate category $(r=+.40 ; p<.01)$ on 46 cases.

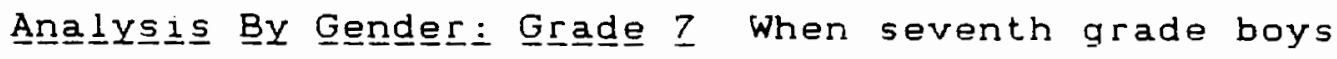
reports of SI were correlated with mothers' reports, the results were low $(r=+.32 ; p<.01)$ on 53 cases. For seventh grade boys and their fathers, the correlation was similar and stayed within the low range $(r=+.36 ; p<.05)$ on 36 cases. 
The correlation jumped into the moderate category for seventh grade girls and their mothers $(r=+.46 ; p<.001)$ based on 47 cases. It dipped back into the low range for seventh grade girls and fathers $(r=+.33 ; p<.05)$ on 30 cases.

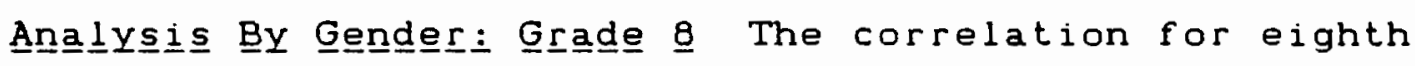
grade boys' SI with their fathers' SI was much stronger than with their mothers. For eighth grade boys and their fathers. a substantial relationship was shown $(r=+.58 ; p<.091)$ based on 27 cases, for eighth grade boys and their mothers, the results were non-significant ( $r=+.25$;ns) based on 41 cases. The results were just the opposite for eighth grade girls. Here there was a substantial relationship for girls and their mothers $(r=+.41 ; p<.01)$ based on 45 cases, and no relationship between eighth grade girls and their fathers $(r=-.01 ; n s)$ on 30 cases.

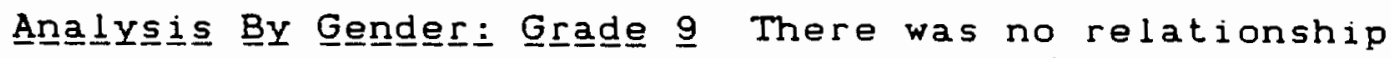
between ninth grade boys' SI with their mothers and their mothers' SI ( $\left.r=+.07 ; n s^{\prime}\right)$ on 24 cases, while ninth grade boys' SI and their fathers' SI showed a substantial relationship $(r=+.47 ; p<.05)$ based on 18 cases. These results held for ninth grade girls as well. For girls and their mothers, there was no relationship $(r=+.06 ; n s)$ on 38 cases. However girls and their fathers showed a low relationship cr=+.36;p $(.05)$ on 28 cases. 
TABLE XX

RELATIONSHIP BETWEEN ADOLESCENT RELATIONAL SATISFACTION WITH MOTHERS AND MOTHERS' RELATIONAL SATISFACTION WITH ADOLESCENTS FOR ALL FAMILIES

\begin{tabular}{|c|c|c|c|c|c|}
\hline & & & $r$ & $p$ & $\mathrm{n}$ \\
\hline$A \perp 1$ & adole & escents & +.26 & $<.001$ & 259 \\
\hline Boy & & & +.22 & $<.01$ & 119 \\
\hline Gir & & & +.30 & $<.001$ & 140 \\
\hline A 11 & 7 th $\mathrm{g}$ & graders & +.39 & $<.001$ & 100 \\
\hline$A 11$ & $8 \mathrm{th} g$ & graders & +.31 & $<.01$ & 86 \\
\hline$A 11$ & 9 th g & graders & +.09 & ns & 62 \\
\hline $7 \mathrm{th}$ & grade & boys & +.32 & $<.01$ & 53 \\
\hline 8 th & grade & e boys & +.25 & ns & 41 \\
\hline 9 th & grade & e boys & +.07 & ns & 24 \\
\hline $7 \mathrm{th}$ & grade & egirls & +.46 & $<.001$ & 47 \\
\hline 8 th & grade & girls & +.41 & $<.01$ & 45 \\
\hline 9 th & grade & girls & +.86 & ns & 38 \\
\hline
\end{tabular}

TABLE XXI

RELATIONSHIP BETWEEN ADOLESCENT RELATIONAL SATISFACTION WITH FATHERS AND FATHERS' RELATIONAL SATISFACTION WITH ADOLESCENTS FOR ALL FAMILIES

\begin{tabular}{|c|c|c|c|c|}
\hline \multicolumn{3}{|c|}{$r$} & $\mathbf{p}$ & $\mathrm{n}$ \\
\hline \multicolumn{5}{|c|}{-------------} \\
\hline \multirow{2}{*}{\multicolumn{2}{|c|}{$\begin{array}{l}\text { A11 adolescents } \\
\text { Boys }\end{array}$}} & +.38 & $<.001$ & 174 \\
\hline & & +.46 & $<.001$ & 82 \\
\hline \multicolumn{2}{|c|}{ Girls } & +.29 & $<.01$ & 92 \\
\hline A 11 & 7 th graders & +.35 & $<.01$ & 66 \\
\hline A 11 & 8th graders & +.39 & $<.001$ & 57 \\
\hline A 11 & 9th graders & +.40 & $<.01$ & 46 \\
\hline 7 th & grade boys & +.36 & $<.05$ & 36 \\
\hline 8 th & grade boys & +.58 & $<.001$ & 27 \\
\hline 9 th & grade boys & +.47 & $<.05$ & 18 \\
\hline 7 th & grade girls & +.33 & $<.05$ & 30 \\
\hline 8 th & grade girls & -.01 & ns & 30 \\
\hline $9 \mathrm{th}$ & grade girls & +.36 & $<.05$ & 28 \\
\hline
\end{tabular}




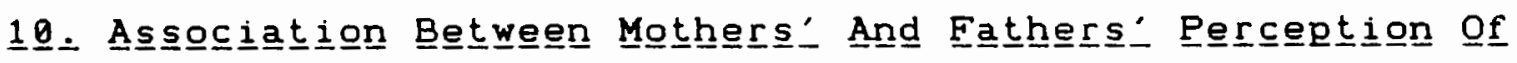

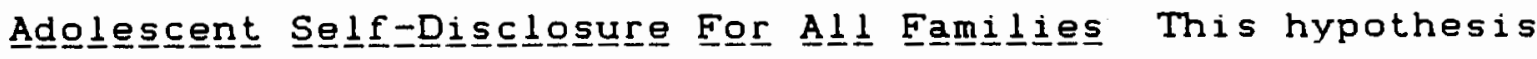
addressed the relationship between mothers' and fathers' perception of adolescent SD. Here there was a moderate correlation. $+.47(p<.001)$ on 282 cases (see Table XXI I).

TABLE XXI I

RELATIONSHIP BETWEEN MOTHERS' AND FATHERS' PERCEPTION OF ADOLESCENT SELF-DISCLOSURE FOR ALL FAMILIES

$r$

$+.47$

$-$

$\mathrm{p}$

n

Mothers' and fathers'

perception of

adolescent self-disclosure
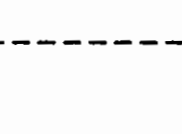

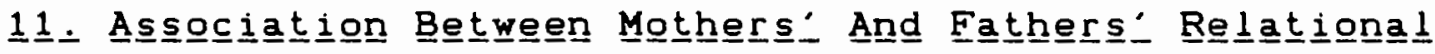

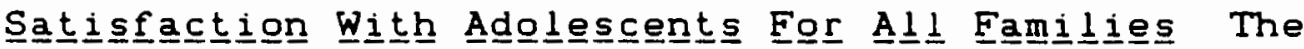

relationship between mothers' and fathers' reports of their relational SI with their adolescents showed a somewhat high correlation, $+.60(p<.001)$ based on 202 cases (see Table $\mathrm{XX}$ I I I )

TABLE XXIII

RELATIONSHIP BETWEEN MOTHERS' AND FATHERS' RELATIONAL SATISFACTION WITH ADOLESCENTS FOR ALL FAMILIES

Mothers' and

fathers' satisfaction

with adolescents 


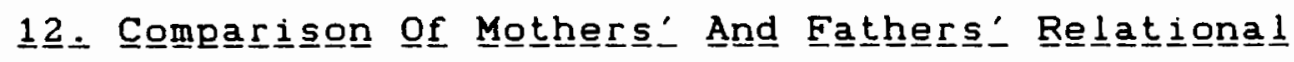

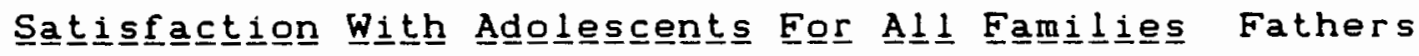
reported more satisfaction with their adolescents than did mothers $(t=2.06 ; p<.05)$ based on reports from 320 mothers and 220 fathers (see Table XXIV).

TABLE XXIV

COMPARISON OF FATHERS' VERSUS MOTHERS' RELATIONAL SATISFACTION WITH ADOLESCENTS FOR ALL FAMILIES

$\begin{array}{lllllll} & M & \text { s.d. } & \text { s.e. } & \text { d.f. } & \text { t } & \text { p } \\ \text { Mothers } & 47.32 & 16.66 & 0.93 & & \\ \text { Fathers } & 50.27 & 16.26 & 1.10 & 539 & 2.06 & <.05\end{array}$

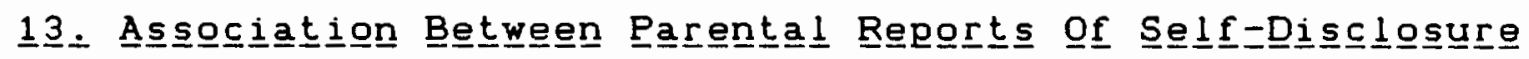

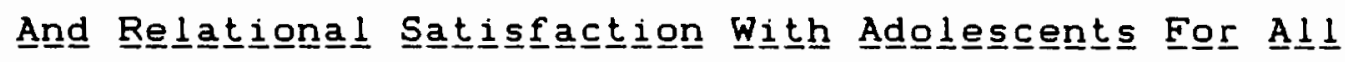
Fanmili ies For mothers, there was a moderate relationship $(r=+.48 ; p<.001)$ based on 320 cases. The correlation was lower for fathers, yet within the moderate range $(r=+.38 ; p$ $<.001$ ) on 220 cases (see Table XXV). 
TABLE XXV

RELATIONSHIP BETWEEN MOTHERS' AND FATHERS'

PERCEPTION OF ADOLESCENT SELF-DISCLOSURE AND

RELATIONAL SATISFACTION FOR ALL FAMILIES

r

$\mathrm{p}$

Mothers' perception of

adolescent self-disclosure

with satisfaction

$+.48$

$<.801$

328

Fathers' perception of

adolescent self-disclosure with satisfaction

$+.38$

$<.001$

220 
CHAPTER IV

DISCUSSI ON

\section{PRIMARY HYPOTHESES}

\section{HYYRotㅡ느토ㅁㅗㅗ I}

There was only a slight relationship (10's, $\left.20^{\prime} s\right)$ found between adolescent self-disclosure and parental perception of that self-disclosure for all families, contrary to the predictions made about this hypothesis. However the results changed dramatically when calculations were done by gender and grade level of the adolescents. The correlation between eighth grade boys' and their fathers' perceptions of selfdisclosure was strong (70's), whereas the correlation between eighth grade boys' and their mothers' was low (20's). Analysis of the data also showed a moderate (40's) connection between self-disclosure by seventh grade girls and the perception of that self-disclosure by their mothers. However seventh grade girls' and their fathers' reports were not associated $(-.09)$. Overall, the correlation between adolescent boys' reports and their fathers' was greater (40's) than that between adolescent girls and their fathers 
$(-.009)$. Although the correlation between self-disclosure by girls and their mothers was slight $\left(20^{\circ} \mathrm{s}\right)$, It was greater than that between boys and their mothers. These conclusions were drawn after adolescent reports of self-disclosure were related to parental perceptions of such messages.

One significant trend emerged from this hypothesis. There was a strong relationship between adolescent boys' reports of self-disclosure to their fathers and fathers' reports of self-disclosure from their sons. This contradicts earlier studies which showed there was a dominant relationship between mothers and sons. Without question. fathers are more in touch with adolescents' perception of their self-disclosure than are mothers. One contributing factor could be the trend of more women returning to work and spending less time with their children.

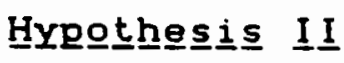

There was a definite moderate (40's) relationship shown between adolescents' self-disclosure reports and reported rolational satisfaction with their parents in all families. This had been predicted. Although the association was quite similar for adolescent boys and girls with their mothers (40's), differences arose when calculations were done by grade level and by gender. For boys and their mothers, seventh graders produced the highest agreement $\left(60^{\prime} \mathrm{s}\right)$, indicative of the sensitivity of sharing personal 
information to relational satisfaction, while ninth grade boys showed no relationship (.0007). Turning to girls and their mothers, eighth graders produced the highest scores $\left(60^{\circ} \mathrm{s}\right)$. But, as in the case of boys and their mothers, ninth graders showed the weakest relationship ( $\left.30^{\prime} s\right)$.

For fathers, boys indicated a greater willingness $\left(50^{\prime}\right.$ s) to self-disclose based on relational satisfaction than girls $\left(40^{\circ}\right)^{\prime}$. The relationship between those variables was the strongest for eighth and ninth grade boys ( $\left.60^{\prime} \mathrm{s}\right)$, while for girls, surprisingly, the relationship between self-disclosure and satisfaction with their fathers was strongest when they were ninth graders (high $40^{\prime}$ s), followed by eighth graders (low $40^{\prime} s$ ). The weakest relationship was found between seventh grade girls and their fathers ( $30^{\circ} s$ ).

From this hypothesis, it appears that there is a strong connection between the willingness by seventh grade boys and eighth grade girls to self-disclose to their mothers based on their satisfaction with that relationship. The same could be said about eighth and ninth grade boys and their fathers. After the seventh grade, the relationship between boys' self-disclosure and their relational satisfaction with mothers starts declining, while during the eighth grade, that relationship increases between boys and their fathers. The relationship between self-disclosure and relational satisfaction by girls with their mothers is strongest in the eighth grade. However, in the ninth grade, girls showed a stronger relationship with their fathers than their mothers 
in terms of communication and satisfaction. These findings, which represent all families, demonstrate that there may be optimal times for parents and their adolescents to develop and to strengthen their relationship based on selfdisclosure.

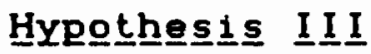

When self-disclosure reports from adolescents were related to parental satisfaction with adolescents for all families, there was a weak ( $\left.20^{\circ} s\right)$ relationship found in reports from mothers and fathers, contrary to predictions. However, when this hypothesis was analyzed in greater depth, a slightly stronger ( $\left.3 \theta^{\prime} s\right)$ relationship was found between girls and mothers and between boys and fathers. Analyzing these data by grade level, the only meaningful result was a slightly moderate $\left(3 \theta^{\prime} s\right)$ correlation between eighth grade girls and their mothers and a moderate (40's) correlation between eighth grade boys and fathers.

These data suggest that there is an association, although slight, between mothers' satisfaction with eighth grade girls and girls' willingness to share personal information. The relationship between these two variables was stronger for eighth grade boys and their fathers. However, when the adolescents' grade level was not a consideration, there was a moderate relationship shown between self-disclosure by adolescents and parental 
satisfaction for girls and their mothers and boys and their fathers. These findings represented reports from all families.

This hypothesis followed the same trend as previous findings and showed a moderate agreement between communication and satisfaction by eighth grade boys and their fathers. It is suggested that there is a greater likelihood of eighth grade boys communicating with their fathers than their mothers if their fathers are more satisfied with their behavior. However, in this correlational design, that speculation can not be substantiated.

\section{Hypothㅡ토몽 IV}

Contrary to predictions, fathers reported receiving more self-disclosure from their adolescents than their mothers in all families. Although this finding could not be calculated by the grade level and the gender of adolescents, the results were surprising in that they deviated from previous reports, which indicated that mothers were favored as recipients of adolescent disclosure. This outcome also was substantiated by earlier results in this study when it was shown that there was a strong correlation between selfdisclosure and relational satisfaction for eighth grade boys and their fathers. This leads the writer to surmise that fathers and their adolescents may have a better 
communication relationship than do mothers. From these findings, it appears that fathers play a greater nurturing role with their adolescent children than hitherto imagined.

\section{FOLLOW-UP ANALYSES}

1. There was a moderate $\left(40^{\prime} \mathrm{s}, 50^{\prime} \mathrm{s}\right)$ relationship found between adolescent boys' and girls' self-disclosure to their mothers and to their fathers from reports for all families. However, when these calculations were broken down by gender and by grade level, several trends emerged. Seventh grade girls and eighth grade boys showed a strong (68's) relationship between their willingness to selfdisclose to mothers and to fathers. However, this strong relationship did not hold for eighth grade girls and ninth grade boys who produced exceedingly low ( $\left.20^{\prime} 5,30^{\prime} 5\right)$ correlations.

These results were yet another indication that there is an optimal time to enhance communication between parents and their adolescents, particularly since, within a year's time, that communication pattern changed drastically. There was a strong association (60's) between seventh grade girls willingness to self-disclose to their mothers and to their fathers. When they reached the eighth grade, this association deteriorated substantially (30's).

The same pattern was true of boys, but at a later age. As eighth graders they showed a stronger relationship 
between self-disclosure with both parents than as ninth graders. One factor contributing to this finding could be that girls mature faster than boys and have an earlier tendency to share personal information with their peers than with their parents. Again, these results are important in understanding the dynamics of family communication because they lend credence to the belief that adolescents are more or less willing to communicate with their parents relative to their grade level (age).

2. Adolescents living in two-parent families reported a greater willingness to communicate with their fathers than with their mothers. This trend continued when a comparison was made on reports by mothers versus fathers. In both instances, adolescents expressed more willingness to communicate with their fathers than with their mothers. However, the reports from boys in this analysis were statistically non-significant.

This finding also adds credence to the strong communication role played by fathers. It becomes even more significant because of the results of an earlier hypothesis, which showed that fathers in two-parent families reported receiving more self-disclosure messages from adolescents than mothers. Undoubtedly adolescents feel more comfortable communicating with their fathers than with their mothers in two-parent families. Furthermore, fathers appear to be more keenly aware of their adolescents' willingness to communicate, be it low or high. 
3. When reports of adolescent self-disclosure to fathers in two-parent families were compared by grade level, a significant trend emerged. Ninth graders were more willing to self-disclose, followed by eighth, then seventh graders.

This finding is interesting because previous analyses indicated a high correlation between self-disclosure reports from eighth graders to their parents, particularly boys, and between seventh grade girls and their mothers.

However, further analysis of these findings presents quite a different picture. When the correlations were computed for adolescents' reports of self-disclosure to their fathers with adolescent satisfaction with that relationship, eighth grade girls and boys achieved the highest correlations $\left(60^{\prime} s\right)$. A similar pattern held when adolescent reports of self-disclosure to their fathers were related to their fathers' satisfaction with adolescents. Although in this finding, the correlations were low, as shown by eighth grade girls and eighth grade boys (20's), the correlations for eighth graders were higher than for seventh and ninth graders. This substantiates the finding that adolescents, particularly eighth graders, are much more willing to share personal information when they experience satisfaction with that relationship.

Adolescent reports of self-disclosure by grade level to mothers in two-parent families produced similar findings as reports to fathers. Again ninth graders had the highest correlations, then eighth and seventh graders. When self- 
disclosure was related to satisfaction, ninth grade girls produced the lowest correlations, followed by eighth, then seventh graders. This adds further credence to the finding that the strongest relationship between self-disclosure and satisfaction occurs between eighth grade girls and their mothers even though the level of self-disclosure increases when girls enter the ninth grade.

4. When adolescent reports of self-disclosure to mothers versus fathers for all families were compared, fathers were again the prime recipient of communication. This finding substantiated earlier results of selfdisclosure reports by adolescents to their parents in twoparent families, which indicated that adolescents were more willing to self-disclose to their fathers than their mothers.

5. The relationship between adolescent satisfaction with their mothers and fathers in all families also resulted in a significant finding. There was a moderate relationship (50's) shown between satisfaction by boys with their mothers and that with their fathers. The relationship for girls and their mothers and fathers was somewhat lower (40's), however it was still within the moderate range. The sharp distinctions arose when calculations were done by gender and by grade level. Eighth grade boys reported the highest correlations $\left(70^{\circ} 5\right)$ with their mothers and fathers, indicating that they were equally satisfied or dissatisfied with both parents. However, the score dropped back down into 
the moderate range $\left(40^{\prime} s\right)$ when calculations were done between ninth grade boys and their parents ( $40^{\prime} s$ ). Among girls, seventh graders reported the strongest relationship $\left(60^{\circ}\right)^{\prime}$, however their levels did not reach those of boys. As was true of boys, the correlations for girls dropped when they entered the ninth grade $\left(40^{\prime} 5\right)$. These findings indicate that eighth grade boys and seventh grade girls are the most satisfied with their parents.

Earlier, in hypothesis I, correlations were computed between reports of adolescent self-disclosure to both parents. Here, seventh grade girls and eighth grade boys produced the highest correlations. This latest finding indicates that there is a strong correlation between relational satisfaction by adolescents with their parents at these same grade levels. Taken together, these findings demonstrate that not only is there an optimal time to enhance the relationship between adolescents and parents, but also to encourage effective communication.

6-8. These analyses examined adolescent relational satisfaction with mothers versus fathers by gender and grade level in two-parent families and all families.

Unfortunately, all these results failed to achieve statistical significance.

9. An earlier analysis examined adolescent relational satisfaction and satisfaction by parents. In this analysis, those calculations were done between adolescents and mothers and adolescents and fathers for all families. From these 
results, there was a higher correlation between satisfaction by girls and mothers ( $\left.30^{\prime} s\right)$ than between boys and mothers $\left(20^{\circ} 5\right)$. However, in both cases, the results were in the weak category. The most substantial differences arose by gender within grade level. Seventh grade girls and their mothers' produced the highest correlation (high $40^{\prime}$ s), followed by eighth grade girls (low $\left.40^{\circ} \mathrm{s}\right)$. The correlation dropped markedly when girls reached the ninth grade (86). For boys, there was a similar pattern, with the highest correlations occurring between seventh grade boys and their mothers $\left(30^{\prime} 5\right)$, followed again by eighth grade boys (20's) and ninth grade boys (.07). This finding indicates that mothers and their seventh grade sons and daughters agree most about the satisfaction within their relationship. That agreement was non-existent during the ninth grade for both boys and girls, according to this analysis.

For adolescents and their fathers, there was a higher correlation produced between boys than girls, with eighth grade boys having the highest correlation (50's), followed by ninth grade boys $\left(40^{\prime} s\right)$, then seventh grade boys. For girls, meanwhile, ninth graders had the highest correlation $\left(30^{\prime} s\right)$, followed by seventh graders $\left(30^{\prime} s\right)$, then eighth graders with no association at all (-.01). Fathers and their eighth grade sons had the most agreement of their relationship based on these findings.

When an earlier analysis was done, the results indicated that the optimal time to build a satisfactory 
relationship was between eighth grade boys and seventh grade girls and their parents. Now, with specific findings that relate to mothers and fathers, it has been shown that the optimal time to build a satisfactory relationship is between eighth grade boys and ninth grade girls and their fathers and between seventh grade girls and seventh grade boys and their mothers. This substantiates earlier findings which related to parental satisfaction with their adolescents and their perceptions of self-disclosure. Also, from these findings, it can be shown that the most difficult time to build a significant relationship between parents and adolescents is between ninth grade boys and girls and their mothers and between eighth grade girls and their fathers. 10-11. When the perception of adolescent selfdisclosure was analyzed for mothers and fathers for all families, a moderate correlation was produced. However, the correlations between parents' indication of relational satisfaction with adolescents were much higher. Obviously, parents have stronger agreement on satisfaction, whether it be negative or positive, than on their perception of selfdisclosure. In part, this could be attributed to societal expectations, which hold that teenagers will exhibit less satisfactory behavior than other children.

12. Fathers indicated more more satisfaction with adolescents than mothers for all families. In an earlier finding, adolescents indicated a stronger relationship between relational satisfaction with their fathers than 
mothers. Also, previous findings showed a higher communication relationship by adolescents to their fathers, with fathers substantiating this finding. Obviously this result gives further indication of a strong relationship between adolescents and their fathers.

13. Fathers' correlations were lower (30's) than mothers' (40's) between adolescent self-disclosure and satisfaction for all families. These results could be attributed to the traditional role played by fathers within the family. Fathers have been regarded as the least likely parent to communicate with adolescents. In this analysis, tradition could have a self-fulfilling prophecy effect, with fathers falsely assuming that their children are more ready to communicate with their mothers. Meanwhile, mothers also may be under the mistaken impression that their adolescents are more willing to share personal information with them rather than with fathers. Awareness of these findings could lead to better communication within families.

\section{LIMITATIONS}

This study overlooked at least one significant area of research. When data were gathered for parents and their adolescents, information was not obtained from the parents about the gender and the grade level of their adolescents. Such results could have lent more credence to the conclusions of this study and would have provided a check on 
adolescent reports of self-disclosure and satisfaction by gender and grade levels.

Although this sample did not isolate families by socioeconomic factors, its large size ( 320 families) and sample method suggest there is no reason to assume that it was not a representative sample. However, the sample possibly did over-represent two-parent families because this population would have been more likely to attend a school function such as Back-To-School-Night.

Furthermore in conducting this study, this investigator gained the consent of the families who attended Back-ToSchool-Night. Because this was a voluntary and, therefore a select group, it could have been more homogeneous than had the group been chosen at random. An attempt was made to circumvent this possibility by selecting families from eight different schools and several socio-economic areas.

\section{MPL I CAT IONS}

Even though the literature is replete with findings that indicate mothers are the prime recipient of selfdisclosure by adolescents, this study contradicted those findings. In several hypotheses, fathers were the prime recipients of self-disclosure by theis adolescents, particularly by eighth grade boys.

There were other significant findings in this research project. They included the following: 
1. A strong relationship was found between reports of self-disclosure and satisfaction by eighth grade boys with their fathers.

2. There was a strong positive relationship between the willingness to share personal information by seventh and eighth grade girls and satisfaction with their mothers. A surprising low relationship in that respect was found between ninth grade girls and their mothers.

3. There was a strong relationship between eighth graders' willingness to self-disclose to their mothers and fathers and their relational satisfaction. Although ninth graders reported higher levels of self-disclosure, such communication was not closely related to satisfaction. Since the strongest pattern between self-disclosure and satisfaction occurred between eighth graders and their parents, efforts should begin early to enhance that relationship.

4. When they were more satisfied with the relationship, boys were more willing to communicate with their parents than girls.

5. In two-parent families, adolescents chose fathers over mothers as the prime recipient of their disclosures. 6. Fathers reported receiving more self-disclosure messages from their adolescents than mothers reported receiving. In their own reports, completed independently, adolescents confirmed this finding. This is clearly the most important finding of the present study. It may indicate that 
because of societal changes fathers are participating more in family communication. This could be related to the increasing number of women who are returning to the work force and the changing composition of the family.

\section{RECOMMENDAT I ONS}

More research needs to be done on communication within families with adolescents to explore the strong communication relationship between $f$ athers and their adolescents. More specifically, an analysis could be done based upon the three factors within the wheeless selfDisclosure Instrument, which include intimacy, valence and the amount of personal information shared. Separate reliability correlations were computed for these factors, and they were reasonably reliable.

A further analysis could be based on the effect siblings have in the self-disclosure process. For example, parental receipt of self-disclosure may be lower when siblings are potential listeners. Another study could analyze communication between adolescents and their parents based on family composition, looking at the traditional family, the step-parent family and the single-parent family to determine whether there are any significant differences. Finally, although it was beyond the scope of the present study, a factor analysis could be performed on the SD and the SI instruments in order to refine them and the theoretical variables they purport to measure. 


\section{REFERENCES}

Barnes, Howard and Olson, David. "Parent-Adolescent Communication and the Circumplex Model. "Chíl

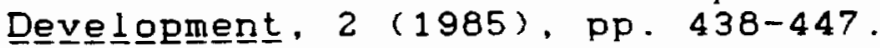

Bradac, James, Hosman, Lawrence and Tardy, Charles. "Disclosure Styles and a Hint at Their Genesis."

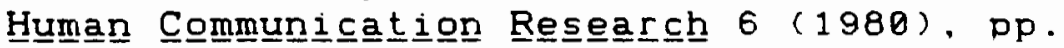
$228-238$.

Campbel1, Ernest. "Adolescent Socialization." In

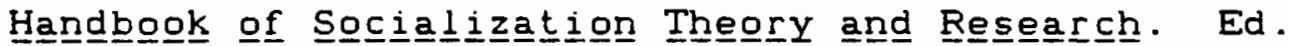
David Goslin. Chicago: Rand McNally, 1969, pp. 821-859.

Chelune, Gordon. "Reactions to Male and Female

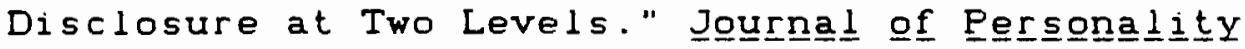

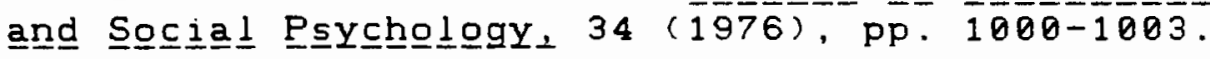

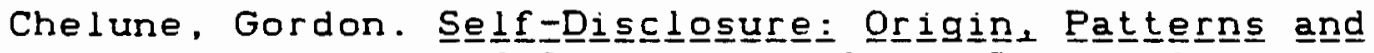

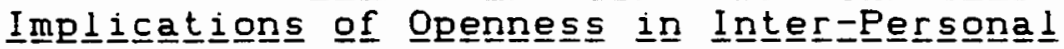

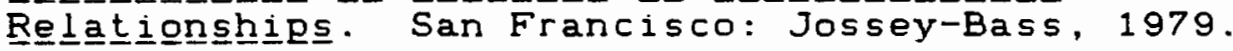

Chelune, Gordon. "Toward an Empirical Definition of Self-Disclosure: Validation in a Single Case

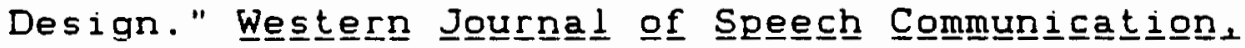
45 (1981), Pp. 269-276.

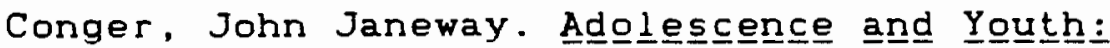

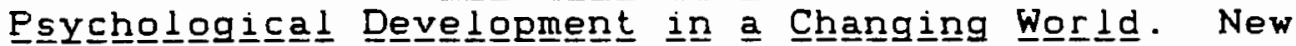
York: Harper and Row, 1973 .

Cozby, Paul. "Self-Disclosure: A Literature Review."

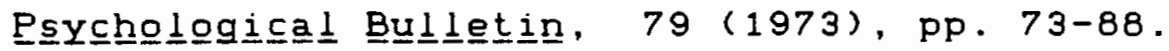

Daluiso, Victor Eugene. "Self-Disclosure and Perception of That Self-Disclosure Between Parents and Their Teenage Children." Unpublished doctoral dissertation. United States International University, 1972 .

Derlega, Valarian and Chaikin, Alan L. "Norms Affecting

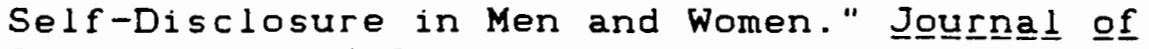

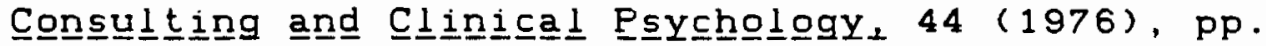
$376-380$.

Doster, Joseph and Strickland, Bonnie Ruth. "Perceived Child-Rearing Practices and Self-Disclosure

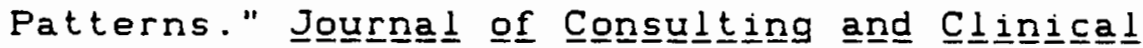
Psyychol ogy, $33(1969)$, p. 382 . 
Douvan, Elizabeth and Adelson, Joseph. The Adgolessceㅡ논 Exper $\underline{\text { enence }}$. New York: John Wiley and Son, 1966.

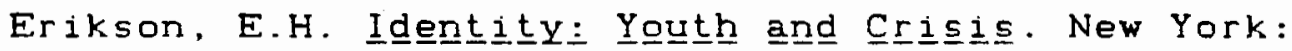
Norton, 1968 .

Foeller, Marguerite L. "Satisfaction and Quality:

Patient Perspectives in Medical Care." Unpublished master's thesis. Portland State University, 1984.

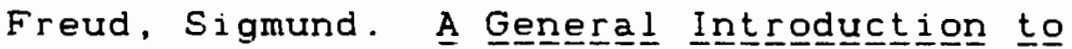

Psychonanalysis (Joan Riviere, trans.). New York: Permabooks, 1953.

Gilbert, Shirley. "Self-Disclosure, Intimacy and

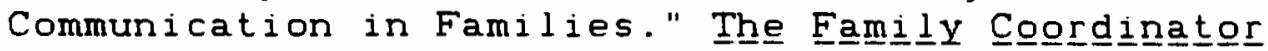
$(1976)$, pp. 221-231.

Goodstein, Leonard and Reinecker, Virginia. "Factors

Affecting Self-Disclosure: A Review of the Literature." In Progress $\underline{\text { In }}$ Experiment

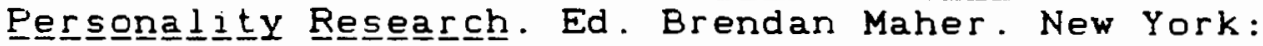
Academic Press, 7 (1974), pp. 49-77.

Greenblatt, Lynda, Freimuth, Vicki and Hasanauer, James. "Psychological Sex Type and Androgyny in the Study of Communication Variables: Self-Disclosure and Communication Apprehension."

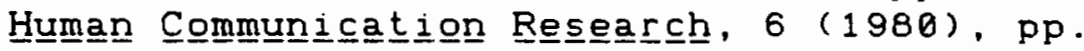
117-129.

Grounds, Linda and Jacob. Theodore. "Assessment of Conflict and Accord." Unpublished manuscript. University of Pittsburgh, 1980.

Grounds, Linda. "Instrumental Behavior and Affect Expression During Family Interaction. Unpublished doctoral dissertation. University of Pittsburgh. 1984 .

Grounds, Linda. "The Development of a Behavioral Instrument with Which to Measure Daily Events in Family Relationships." Unpublished master's thesis. University of Pittsburgh, 1979.

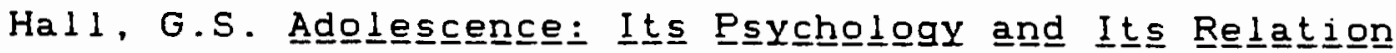

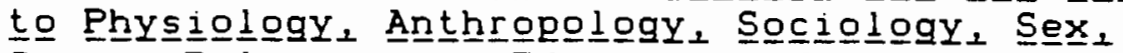

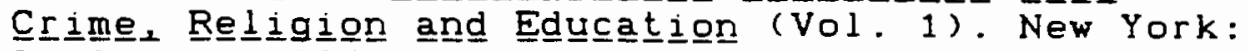
Appleton, 1904,1905 .

Hecht, Michael. "Measures of Communication Satisfaction." Human Communi (1978b), pp. 350-368. 
Hecht, Michael. "The Conceptualization and Measurement of Interpersonal Communication Satisfaction."

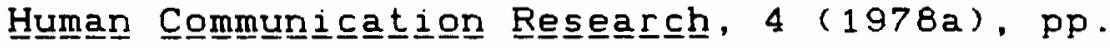
$253-263$.

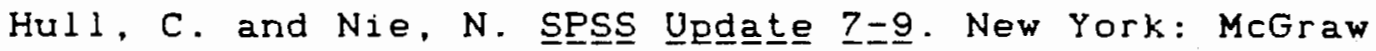
Hill, 1981 .

Jackson, Don D. "The Study of the Family." Fam $4(1965)$, pp . 1-17.

Jacob, Theodore and Seilhamer, Ruth Ann. "Adaptation of the Area of Change Questionnaire for Parent-Child Relationship Assessment." Unpublished manuscript. University of Pittsburgh, 1984 .

Jacob, Theodore, Grounds, Linda and Haley, Rita. "Correspondence Between Parents" Reports on the

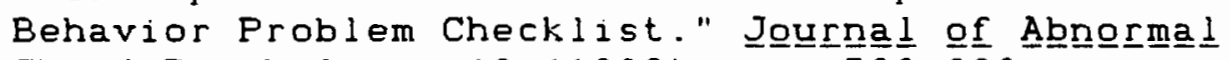

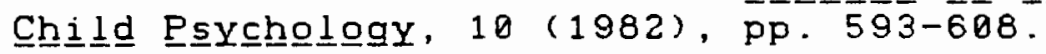

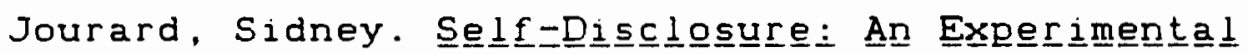

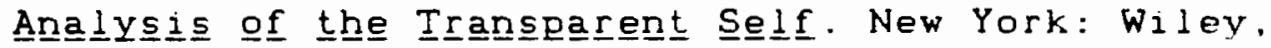
1971 .

Jourard, Sidney and Lasakow, Paul. "Some Factors in

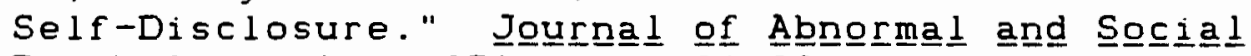
Psych므으으, $56(1958)$, pp. $91-98$.

Kagan, Jerome. "A Conception of Early Adolescence." In

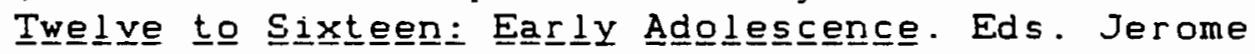
Kagan and Robert Coles. New York: W.W. Norton. 1972 , pp. 91-100.

Kelly, Clifford $W$., Chase, Lawrence J. and Tucker, Raymond K. Replication in Experimental

Communication Research: An Analysis. Human

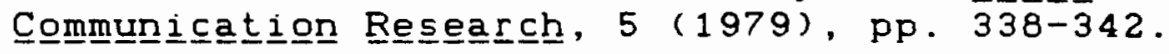

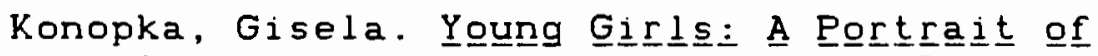

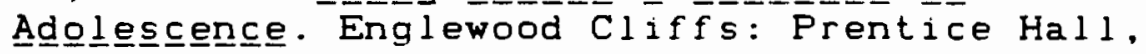
1976 .

Lovins, Alan. "Reciprocity of Self-Disclosure Between Adolescents and Their Parents." Unpublished doctoral dissertation. Columbia University, 1976.

Margolin, G., Talovic, S. and Weinstein, C.D. "Areas of Change Questionnaire: A Practical Approach to

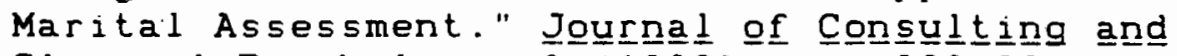

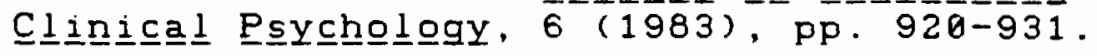


Margolin, Gayla. "Relationships Among Marital

Assessment Procedures, A Correlational Study."

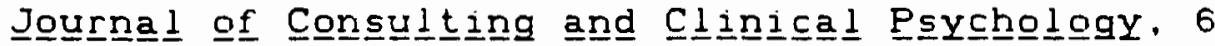
$(1978)$, pp. 1556-1558.

Miller, Gerald R. and Sunnafrank, Michael, J.

"Theoretical Dimensions of Applied Communication

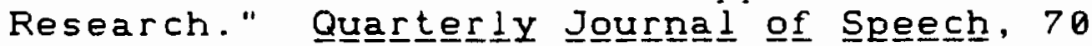

(1984), pp. 255-263.

Mussen, P.H., Conger, J.J. and Kagan, J. Chhi $\underline{1}$ d

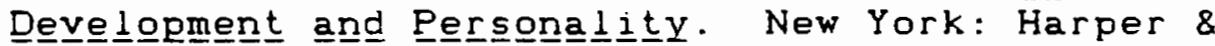
Row, 1969 .

Norrell, J. Elizabeth. "Self-Disclosure: Implications for the Study of Parent-Adolescent Interaction."

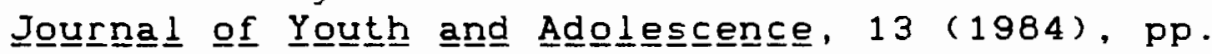
$163-78$.

O'Neill, Sylvia, Fein, Deborah, Volit, Kathryn McColl and Frank, Constance. "Sex Differences in Pre-Adolescent Self-Disclosure." Sex Role로, 2 (1976), pp. 87-88.

Pasley, Kay and Gecas, Viktor. "Stresses and

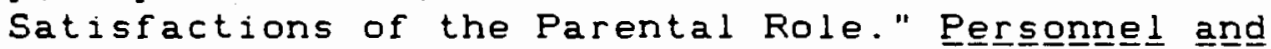

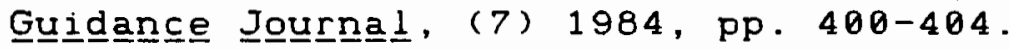

Patterson, G.R. "Some Procedures for Assessing Changes

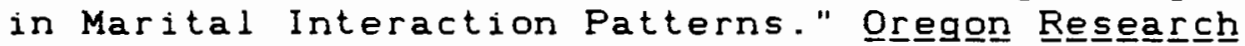

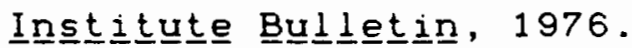

Pearce, $W$. Barnett and Sharp, Stewart. "Self-Disclosing

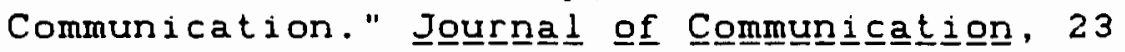
(1973), pp. 409-425.

Pedersen, Darhl and Highbee, Kenneth. "Personality

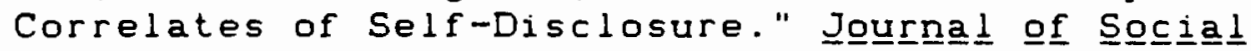
Psy드느의은, 78 (1969), pp. 81-89.

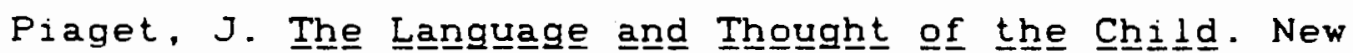
York: World, 1962 .

Prinz, Ronald, Rosenblum, Renee and O'Leary, K. Daniel. "Affective Communication Differences Between Distressed and Nondistressed Mother-Adolescent

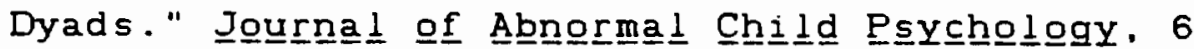
(1978), pp. 373-383.

Rivenbark, W.H. "Self-Disclosure Patterns Among

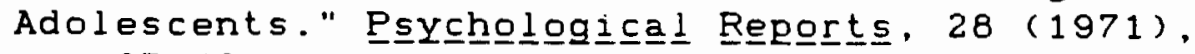
pp. $35-42$. 
Rosenfeld, Lawrence. "Self-Disclosure Avoidance: Why I Am Afraid to Tell You Who I Am." Conmmuni Monnoㅡ므므는, $46(1979)$, pp. 63-74.

Satir, Virginia. Conjoint Family Then Science and Behavior Books, 1967.

Snoek, Diedrick and Rothblum, Esther. "Self-Disclosure Among Adolescents in Relation to Parental

Affection and Control Patterns." Adoㅡ르트트므드, 14 $(1979), \mathrm{pp} .333-340$.

Tardy, Charles, Hosman, Lawrence and Bradac, James. "Disclosing Self to Friends and Family: A

Re-examination of Initial Questions."

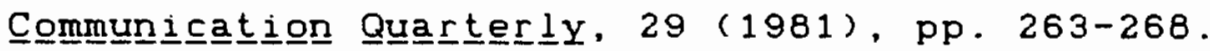

Tims, Albert and Masland, Jonathan. "Measurement of

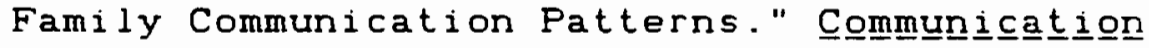
Reㅡ트르도느, $12(1985)$, pp. 335-357.

Vondracek, Sarah and Fred. "The Manipulation and Measurement of Self-Disclosure in

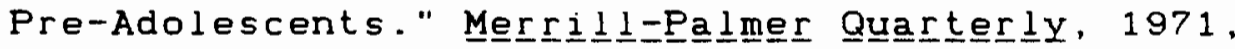
pp. 51-57.

Waterman, Jill. "Family Patterns of Self-Disclosure."

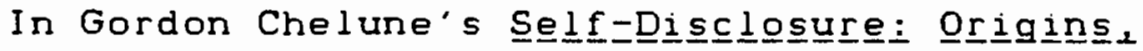

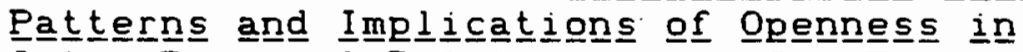

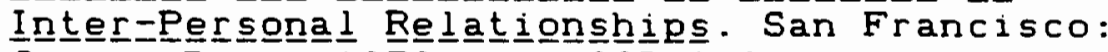

Jossey-Bass, 1979 , pp. $225-242$.

Weiss, Robert L. and Margolin Gayla. "Assessment of Marital Conflict and Accord." In A.R. Ciminero, K.S. Calhoun and H.E. Adams (Eds.) Han믐ook of

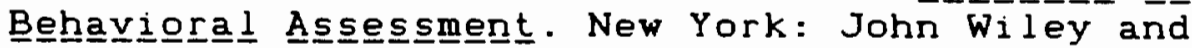
Sons, 1977 , pp. 555-602.

Weiss, R.L., Hops, H. and Patterson, G.R. "A Framework for Conceptualizing Marital Conflict: A Technology for Altering It, Some Data For Evaluating It." In

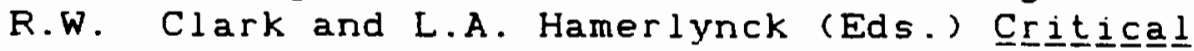

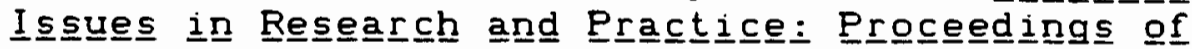
the Fou든

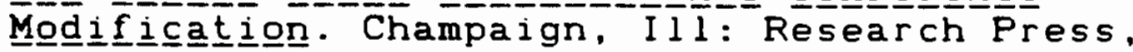
1973 .

Weiss, R.L., and Birchler, G.R. "Areas of Change." Unpublished doctoral dissertation. University of Oregon, 1975 . 
Wheeless, Lawrence and Grotz, Janis. "Conceptualization and Measurement of Reported Self-Disclosure."

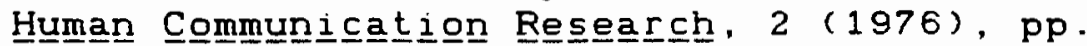
$338-345$.

Wheeless, Lawrence and Grotz, Janis. "The Measurement of Trust and its Relationship to Self-Disclosure."

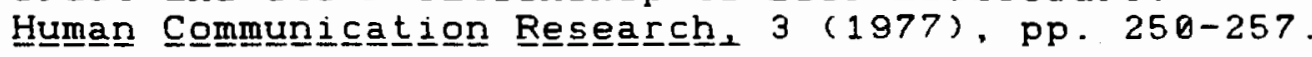

Wheeless, Lawrence. "Self-Disclosure and Interpersonal Solidarity: Measurement, Validation and

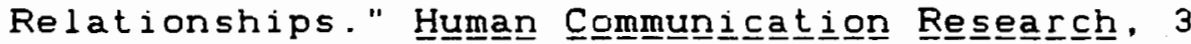
(1976), pp. 47-61.

Wheeless, Lawrence and Grotz, Grotz. "Self-Disclosure and Trust: Conceptualization, Measurement and Inter-Relationships." Paper presented at the annual convention of the. International Communication Association. Chicago, April, 1975.

Williams. Frederick. Rea York: Holt, Rinehart and Winston, 1979 . 
APPENDIX A

PARENT QUESTIONNAIRES

WHEN YOUR CHILD TALKS TO YOU

Please answer the following questions by choosing the most appropriate response, marking your answers on the accompanying sheet.

My child:

1. does not of ten talk about himself/herself.

2. usually says brief things about himself/herself.

3. usually talks for fairly long periods of time.

4. talks the longest when the conversations are about himself /herself.

5. Often talks about himself/herself.

6. often discusses his/her feelings.

7. infrequently expresses personal beliefs and opinions.

8. usually says positive things about himself/herself.

9. Usually shares more negative than positive things.

10. normally reveals bad feelings.

11. normally expresses good feelings.

12. of ten reveals more undesirable than desirable things.

13. usually shares negative things.

14. usually shares more positive than negative things.

15. shares intimate things about himself/herself for a long after getting started.

16. without intending to, reveals information about himself/ herself.

17. often shares intimate things without hesitation.

18. sometimes cannot control the intimate things that helshe shares.

19. intimately reveals information once getting started.

20. I believe that I know my child as well or better than anyone else. 
YOUR CHILD

This questionnaire asks you to indicate your level of satisfaction or dissatisfaction with your child's behavior. Choose the most appropriate response, marking your answers on the accompanying sheet.

My child:

1. keeps his/her room clean and neat.

2 . comes to meals on time.

3. pays attention to his/her appearance.

4. spends time with kids his/her own age.

5. shows me respect.

6. spends time at home with the family.

7. takes responsibility for homework.

8. talks to me about problems.

9. shows an interest in school.

10. spends money responsibly.

11. controls his/her temper.

12. gets together with friends.

13. shows appreciation for the things I do.

14. helps with chores when asked.

15. assumes responsibility for his/her behavior.

16. spends time with me.

17. uses money responsibly.

18. Iistens to what I have to say.

19. makes his/her own decisions.

20. shows concern for brothers and sisters.

21. enjoys being with the family.

22. is outgoing and friendly.

23. seems realistic about goals.

24. values my advice.

25. seems reasonably well adjusted.

26. argues with me.

27. is comfortable with adult friends of the family.

28. is comfortable with family relatives.

29. participates in family discussions. 


\section{APPENDIX B}

\section{ADOLESCENT QUESTIONNAIRES}

\section{CONSENT FORM}

I agree to participate in a research project on adolescent-parent communication and satisfaction conducted by Diane Lund, a graduate student at Portland State University.

I understand that this study, which my parents have already participated in, explores family communication.

I have been assured that all information I give will be kept strictly confidential and that the identity of all subjects will remain anonymous.

\section{INSTRUCTIONS}

Think about how of ten you talk with your mother and father. Do those conversations last a long time? What kind of information do you share with them?

These are among the questions in this survey. There are no right or wrong answers. Simply choose the responses closest to your personal feelings. There are separate questionnaires for your mother and father.

Read each item carefully, filling in only one box on the answer sheet for each question. 
For example:

I of ten discuss feelings about myself with my mother. Agree Undecided Disagree 1 2 3

4 5

6 7

Strongly Moderately

Moderately Strongly

Agree Agree

Disagree

Disagree

If you strongly agree with this statement, you should fill in the number 1 box.

If you moderately disagree with this statement, you should $f 11$ in the number 5 box on the answer sheet.

Please do not leave any item blank and do not make any mark on the answer sheet except in the appropriate boxes. When marking your answers, use only a No. 2 pencil, making a mark between the box lines. Mark only one box per question. 
TALKING WITH YOUR MOTHER

Please answer the following questions by choosing the most appropriate response, marking your answers on the accompanying sheet.

1. I do not of en talk about myself to my mother.

2. My statements about myself to my mother are usually brief.

3. I usually talk about myself for fairly long periods of time with my mother.

4. My conversations with my mother last the least amount of time when I'm talking about myself.

5. I of ten talk about myself with my mother.

6. I often discuss my feelings about myself with my mother.

7. I do not of ten express my personal opinions and beliefs with my mother.

8. I usually say good things about myself to my mother.

9. What I say about myself to my mother is usually more negative than positive.

10. I normally share bad feelings about myself with my mother.

11. I normally share good feelings about myself with my mother.

12. I of ten say more bad things than good things about nyself to my mother.

13. I usually share bad things about myself with my mother.

14. My statements about myself to my mother are usually more positive than negative.

15. I intimately talk about who "I really am" with my mother.

16. Without meaning to, I typically share things about myself with my mother.

17. I of ten hesitate to say intimate things about myself to my mother.

18. Sometimes intimate things about myself slip out when I'm talking with my mother.

19. Once I get started, I talk intimately about myself to my mother.

26. My mother knows me better than my friends. 
MY MOTHER

This questionnaire asks you to indicate how satisfied or dissatisfied you are with your mother's behavior toward you. Choose the most appropriate response, marking your answers on the accompanying sheet.

My mother:

1. pays attention to me.

2. does things with me.

3. sees that meals are ready on time.

4. leaves me to myself when I want to be alone.

5. shows appreciation for the things $I$ do well.

6. gives me responsibility around the house.

7. helps me with my homework.

8. lets me make my own decisions.

9. lets me wear the clothes I like.

10. allows me to spend free time as I choose.

11. Iistens to what I have to say.

12. tries to understand how I feel.

13. is nice to my friends.

14. shows me respect.

15. tells me when she's unhappy about the things I do.

16. gives me money whenever I need it.

17. lets me go with my friends whenever I want.

18. spends time with me.

19. treats me like an adult.

20. is interested in my schoolwork.

21. becomes involved in my hobbies and special interests.

22. lets me stay out late at night.

23. controls her temper around me.

24. enjoys being with me.

25. disciplines me when necessary.

26. telis me when I do a good job.

27. makes me do chores.

28. tries to convince me that she's right and I'm wrong.

29. treats me as well as my brothers and sisters. 
TALKING WITH YOUR FATHER

Please answer the following questions by choosing the most appropriate response, marking your answers on the accompanying sheet.

1. I do not of ten talk about myself to my father.

2. My statements about myself to my father are usually brief.

3. I usually talk about myself for fairly long periods of time with my father.

4. My conversations with my father last the least amount of time when I'm talking about myself.

5. I often talk about myself with my father.

6. I often discuss my feelings about myself with my father.

7. I do not often express my personal opinions and beliefs with my father.

8. I usually say good things about myself to my father.

9. What I say about myself to my father is usually more negative than positive.

10. I normally share bad feelings about myself with my father.

11. I normally share good feelings about myself with my father.

12. I often say more bad things than good things about myself to my father.

13. I usually share bad things about myself with my father.

14. My statements about myself to my father are usually more positive than negative.

15. I intimately talk about who "I really am" with my father.

16. Without meaning to, I typically share things about myself with my father.

17. I of ten hesitate to say intimate things about myself to my father.

18. Sometimes intimate things about myself slip out when I'm talking with my father.

19. Once I get started, I talk intimately about myself to my father.

20. My father knows me better than my friends. 
MY FATHER

This questionnaire asks you to indicate how satisfied or dissatisfied you are with your father's behavior toward you. Choose the most appropriate resporise, marking your answers on the accompanying sheet.

My father:

1. pays attention to me.

2. does things with me.

3. sees that meals are ready on time.

4. Leaves me to myself when I want to be alone.

5. shows appreciation for the things I do well.

6. gives me responsibility around the house.

7. helps me with my homework.

8. lets me make my own decisions.

9. lets me wear the clothes I like.

10. allows me to spend free time as I choose.

11. Iistens to what I have to say.

12. tries to understand how I feel.

13. is nice to my friends.

14. Shows me respect.

15. tells me when he's unhappy about the things I do.

16. gives me money whenever I need it.

17. lets me go with my friends whenever I want.

18. spends time with me.

19. treats me like an adult.

20. is interested in my schoolwork.

21. becomes involved in my hobbies and special interests.

22. lets me stay out late at night.

23. controls his temper around me.

24. enjoys being with me.

25. disciplines me when necessary.

26. tells me when I do a good job.

27. makes me do chores.

28. tries to convince me that he's right and I'm wrong.

29. treats me as well as my brothers and sisters. 